\title{
Peanut Agglutinin and Chondroitin-6-sulfate Are Molecular Markers for Tissues That Act as Barriers to Axon Advance in the Avian Embryo
}

\author{
ROBERT A. OAKLEY* AND KATHRYN W. TOSNEY*, \\ ${ }^{*}$ Neuroscience Program and $†$ Biology Department, Natural Science Building, The University of Michigan, Ann Arbor, Michigan 48109
}

Accepted June 10, 1991

\begin{abstract}
Axon outgrowth between the spinal cord and the hindlimb of the chick embryo is constrained by three tissues that border axon pathways. Growth cones turn to avoid the posterior sclerotome, perinotochordal mesenchyme, and pelvic girdle precursor during normal development and after experimental manipulation. We wanted to know if these functionally similar barriers to axon advance also share a common molecular composition. Since the posterior sclerotome differentially binds peanut agglutinin (PNA) and since PNA binding is also typical of prechondrogenic differentiation, we examined the pattern of expression of PNA binding sites and cartilage proteoglycan epitopes in relation to axon outgrowth. We found that all three barrier tissues preferentially express both PNA binding sites and chondroitin-6-sulfate (C-6-S) immunoreactivity at the time when growth cones avoid these tissues. Moreover, both epitopes are expressed in the roof plate of the spinal cord and in the early limb bud, two additional putative barriers to axon advance. In contrast, neither epitope is detected in peripheral axon pathways. In the somites, this dichotomous pattern of expression clearly preceded the invasion of the anterior sclerotome by either motor growth cones or neural crest cells. However, in the limb, barrier markers disappeared from presumptive axon pathways in concert with the invasion of axons. Since this coordinate pattern suggested that the absence of barrier markers in these axon pathways requires an interaction with growth cones, we analyzed the pattern of barrier marker expression following unilateral neural tube deletions. We found that PNA-negative axon pathways developed normally even in the virtual absence of axon outgrowth. We conclude that the absence of staining with carbohydrate-specific barrier markers is an independent characteristic of the cells that comprise axon pathways. These results identify two molecular markers that characterize known functional barriers to axon advance and suggest that barrier tissues may impose patterns on peripheral nerve outgrowth by virtue of their distinct molecular composition. (1) 1991 Academic Press, Inc.
\end{abstract}

\section{INTRODUCTION}

The development of specific neuromuscular connections in the chick embryo is critically dependent on axon guidance. It has become clear that two distinct and experimentally dissociable classes of guidance cues contribute to the stereotyped pattern of motor axon outgrowth. General cues influence all subpopulations of motor and sensory axons and define the common pathways of nerve outgrowth. In contrast, specific cues influence specific subpopulations of axons and direct the deployment of these subpopulations at points where two or more common pathways diverge (Lance-Jones and Landmesser, 1981a,b; for review see Landmesser, 1988; Tosney, 1991). Although little is known about the cellular and molecular mechanisms that mediate general guidance, common axon pathways could, in theory, be defined by positive influences that promote outgrowth in prospective axon pathways or by negative influences from surrounding tissues that constrain outgrowth to prospective axon pathways. There is strong experimental evidence that common axon pathways are delineated, at least in part, by the less permissive nature of surrounding tissues. In this report we have identified molecular correlates that characterize tissues known to constrain axons during peripheral nerve outgrowth in the chick embryo.

Three tissues that lie adjacent to peripheral nerve pathways have been experimentally established to act as barriers to axon advance based on growth cone responses to surgical manipulations (Tosney and Landmesser, 1984; Tosney, 1988a; Tosney and Oakley, 1990). A structure may be inferred to act as a barrier if axons turn to avoid it during normal development or if it lies adjacent to an axon pathway but is not invaded by axons. However, experimental manipulations are necessary to define whether axon trajectory is dependent on the suspected barrier or on some property of the adjacent pathway. For example, deletion of a bona fide barrier should abolish turning behavior and lead to the spatial expansion of the axon pathway. Similarly, direct confrontation of growth cones with a barrier should elicit turning behavior. The term barrier is thus intended to decribe a structure that has been experimentally shown to provide axon guidance cues that result in growth cone avoidance behavior. The term barrier is not meant to imply a particular mechanism or that the tissue is completely impervious to axonal invasion.

The pelvic girdle precursor was the first barrier tissue to be identified based on these experimental criteria. 
Barrier function is suggested by the pattern of nerve growth; growth cones gather in a plexus that extends along the entire limb base, turn to avoid the girdle precursor, and enter the limb as major nerve trunks only through regions where the girdle mesenchyme is absent (Tosney and Landmesser 1984, 1985). Barrier function was confirmed by deletions; in the absence of the girdle; precursor axons proceed directly into the limb (Tosney and Landmesser, 1984). Since turning behavior is eliminated at the base of the limb and axon pathways expand spatially in the absence of the girdle precursor, axon trajectory in this region is normally dependent on the restriction of axons by a barrier rather than solely on guidance by some feature of the plexus.

The sclerotome of the posterior half of each somite also acts as a barrier to axon advance. Barrier function is suggested by the pattern of axon outgrowth; although motor axons exit the spinal cord opposite both anterior and posterior somite halves, those that encounter the posterior sclerotome turn to avoid it (Dehnbostel and Tosney, 1990). This pattern of initial outgrowth leads to preferential colonization of the anterior half of each somite and the segmental arrangement of the spinal nerves (Keynes and Stern, 1984). Barrier function has been confirmed by deletions and transplantations. In the absence of the sclerotome, axons are not restricted to the anterior half segment; they extend from the spinal cord as a continuous sheet (Tosney, 1987, 1988a). Similarly, transplanted compound somites consisting of multiple posterior half segments exclude motor axons (Stern and Keynes, 1987).

We have recently shown that the anterior sclerotome can be further subdivided into two different functional domains. The dorsal anterior sclerotome acts as a pathway, whereas the perinotochordal mesenchyme (the ventromedial sclerotome that surrounds the notochord) acts as a barrier to axon advance (Tosney and Oakley, 1990). Barrier function was suggested by the pattern of axon outgrowth around the perinotochordal mesenchyme during normal development (Tosney and Landmesser, 1985) and in embryos with hypertrophic notochords (Tosney, 1988a). We confirmed barrier function by rotating the neural tube so as to alter the initial direction of motor outgrowth and directly confront motor growth cones with the perinotochordal mesenchyme. Under these conditions, motor axons turn to avoid the perinotochordal mesenchyme and project around rather than through this tissue at all stages of outgrowth (Tosney and Oakley, 1990).

There is also evidence that the early limb bud may present a barrier to axon invasion. Although axons enter the plexus region adjacent to the limb bud by stage 21 , axons do not enter the limb until stage 24 , a delay of more than a day (Tosney and Landmesser, 1985). Axons also delay entering young limb buds that have been grafted onto older embryos, which suggests that invasion is dependent on properties of the limb bud rather than on growth cone capabilities (Swanson and Lewis, 1982). Moreover, the mesenchyme of the early limb bud has recently been shown to be an inhospitible substrate for motor axon advance in vitro (Landmesser, 1988).

The cellular and molecular mechanisms that mediate barrier function are as yet unknown. Attention has recently focused on characterizing differences between anterior and posterior sclerotome since the former acts as an axon pathway and the latter acts as a barrier. However, differences in the structural organization of sclerotome populations cannot account for these functional differences; neither physical impediments to axon advance in the posterior sclerotome nor aligned elements that could channel axons in the anterior sclerotome have been revealed by scanning and transmission electron microscopy (Tosney, 1988b; Dehnbostel and Tosney, 1990). The functional differences between anterior and posterior sclerotome populations are therefore likely to be related to the differential expression of molecules that can be detected by growth cones. A marker that distinguishes between sclerotome populations is the peanut agglutinin (PNA) binding site ( $\mathrm{Gal} \beta 1-3 \mathrm{Gal}-$ Nac; Lotan et al., 1975), which is preferentially expressed in the posterior sclerotome (Stern et al., 1986) and thus distinguishes a known axon barrier from an adjacent axon pathway.

We wanted to know if all three of the aforementioned functional barriers to axon advance express the PNA binding epitope and if they do so during periods when axons avoid these tissues. In addition, since PNA binding molecules are also expressed by prechondrogenic tissues (Aulthouse and Solursh, 1987), we screened a number of probes to cartilage proteoglycans to determine whether these molecules are also expressed in barrier tissues during axon avoidance. Since barrier tissues are not histologically distinct from axon pathways during early outgrowth, we used tubulin antibodies to reveal both the timing and the pattern of axon outgrowth. We found that the PNA binding epitope and chondroitin-6-sulfate immunoreactivity are expressed by all three barrier tissues during stages of initial axon outgrowth. Neither epitope was detected in axon pathways.

Although these epitopes were not detected in axon pathways, it was unclear if growth cones actually participated in the differential distribution of these barrier markers. For example, the absence of these epitopes in axon pathways could be due to: (1) degradation by proteases released from growth cones (Kryostosek and Seeds, 1981; Pittman, 1985), (2) an interaction between growth cones and the pathway mesenchyme, or (3) the presence of nonstaining axons. We therefore asked if 
the apparent lack of expression in pathways was dependent on axon outgrowth. By analyzing the pattern of PNA binding in the virtual absence of axon outgrowth, we experimentally established that the PNA binding pattern is independent of axon outgrowth.

\section{MATERIALS AND METHODS}

\section{Immunohistochemistry}

White leghorn chick embryos and quail embryos (stage 16-25) were carefully staged using the criteria of Hamburger and Hamilton (1951). Embryos were decapitated, eviscerated, and fixed in $4 \%$ paraformaldehyde with $0.5 \%$ cetylperidinium chloride (CPC) in phosphate-buffered saline (PBS) for $2-4 \mathrm{hr}$ at room temperature. Preliminary experiments showed that inclusion of CPC in the fixative markedly enhanced the binding of PNA to embryonic tissues, particularly in young embryos. Fixed embryos were washed in PBS and then infiltrated in 5\% sucrose (in PBS) for 1-24 hr and in 15\% sucrose for $18-24 \mathrm{hr}$ at $4^{\circ} \mathrm{C}$. Embryos were oriented and embedded in a solution of $7.5 \%$ gelatin (Sigma, 300 bloom) and $15 \%$ sucrose (in PBS) after infiltration for $4-6 \mathrm{hr}$ at $37^{\circ} \mathrm{C}$. After $24 \mathrm{hr}$ at $4^{\circ} \mathrm{C}$ the blocks were rapidly frozen in isopentane cooled on dry ice. Serial $10-\mu \mathrm{m}$ frozen sections were cut through the hindlimb region using a Reichert cryostat. At least five embryos from each stage studied were sectioned in the transverse plane and additional embryos from early stages (16-20) were sectioned in the frontal plane. We used serial sectioning in combination with immunocytochemistry (see below) to determine the timing and pattern of nerve outgrowth in relation to barrier tissues. Since prospective axon pathways are not histologically distinct from barrier tissues, these pathways were defined by comparing nerve patterns in closely staged embryos.

Selected sections were reacted with PNA (Vector) and binding was detected using goat anti-PNA (Vector) and an FITC-conjugated secondary antibody (Sigma). The specificity of PNA binding was confirmed by inhibition experiments using either $\mathrm{D}-(+)$-galactose or asialofetuin (Sigma), which bears the Gal $\beta 1-3$ GalNac epitope (Lotan et al., 1975). Staining was also completely abolished when either PNA or the antibody to PNA was excluded from the protocol. Axons were detected in the same sections using a monoclonal antibody (6-11-B1) directed against acetylated $\alpha$-tubulin (Piperno et al., 1987) followed by a RITC-conjugated secondary antibody (Jackson Immunoresearch). 6-11-B1 has been shown to label most if not all axons at very early stages of development in the zebrafish (Chitnis and Kuwada, 1990). This isoform of tubulin is enriched in axons and labels the entire distal process to the base of the growth cone (Lim et al., 1989; Chitnis and Kuwada, personal communication).
The following protocol was used for the simultaneous localization of axons and PNA binding. PNA was diluted in Hepes-buffered saline (HBS: $10 \mathrm{~m} M$ Hepes, $0.15 \mathrm{M}$ $\mathrm{NaCl}, 0.1 \mathrm{mM} \mathrm{CaCl}{ }_{2}$ ) containing $1 \%$ bovine serum albumin (BSA). Sections were rehydrated in PBS to remove gelatin, blocked for $30 \mathrm{~min}$ in HBS with $1 \% \mathrm{BSA}$ and $1 \%$ normal rabbit serum, incubated for 30 min in PNA (10 $\mu \mathrm{g} / \mathrm{ml}$ ), and washed. Sections were then incubated for 90 min in mixed primary antibodies (anti-PNA, 1:100; 6-11$\mathrm{B} 1, \mathbf{1 : 1 0}$ ), washed, incubated for $90 \mathrm{~min}$ in mixed secondary antibodies (rabbit anti-goat-FITC, rabbit antimouse-RITC; 1:50), washed, and then mounted in PBS:glycerol (1:1).

The distribution of chondroitin-6-sulfate (C-6-S) epitopes was revealed using a monoclonal antibody $(5 / 6 /$ 3B3) generated to chondroitinase ABC-digested chondroitin sulfate of cartilage proteoglycan core protein (Couchman et al., 1984; Caterson et al., 1985). To localize the C-6-S epitope, sections were postfixed in cold $95 \%$ ethanol, rehydrated in PBS, and digested with chondoitinase $\mathrm{ABC}(0.2$ units $/ \mathrm{ml})$ in $0.1 M$ Tris-acetate buffer with $1 \% \mathrm{BSA}$ for $1 \mathrm{hr}$ at $37^{\circ} \mathrm{C}$. Sections were then washed, blocked for $30 \mathrm{~min}$ (as above), incubated for 60 min in 5/6/3B3 (1:50 without Triton), washed, and mounted as above. The distribution of axons in relation to C-6-S immunoreactivity was defined by staining neighboring sections with monoclonal antibody 6-11-B1 as above. Except where noted, all antibodies were diluted in blocking solution containing $0.5 \%$ Triton X-100 (Sigma), all incubations were at room temperature, and all washes were in three changes of PBS.

We tested several other probes to cartilage-related molecules including monoclonal antibodies directed against keratan sulfate oligosaccharides $(1 / 20 / 5 \mathrm{D} 4$; 4/8/1B4 and 4D1) and chondroitinase-digested chondroitin-4-sulfate/dermatan sulfate (Caterson et al., 1983; Couchman et al., 1984; Caterson et al., 1985). Monoclonal antibodies to chondroitin sulfate epitopes and chrondroitinase $\mathrm{ABC}$ were obtained from ICN Biomedical.

\section{Experimental Embryos}

Neural tubes were unilaterally deleted as previously described (Tosney et al., 1988) at stages prior to motor axon outgrowth (stages 16-18) in the lumbosacral region. Briefly, chick embryos were lightly stained with $0.25 \%$ neutral red in distilled water and the neural tube was opened dorsally with a fine tungsten needle. The left half of the neural tube was removed over three to eight presumptive hindlimb segments by aspiration through a small micropipette (tip size 20-40 $\mu \mathrm{m}$ ). Operated embryos were moistened with sterile saline containing 100 units $/ \mathrm{ml}$ of penicillin-streptomycin (GIBCO) and incubated for an additional 12-48 hr. Em- 
bryos that appeared normal aside from the neural tube deletion and the accompanying spina bifida were fixed and processed for double labeling with PNA and 6-11-B1 as described above. We examined 13 embryos with successful neural tube deletions at stages after axons had entered the limb on the unoperated side (stages 25-26). Six of these had major deletions ( $>90 \%$ ) of both sensory and motor populations. These embryos were used to measure the anterior/posterior extent of the PNA-negative dorsal crural nerve pathway. Twelve additional experimental embryos were examined at various earlier stages of outgrowth (stages 19-23).

\section{RESULTS}

\section{Expression of Barrier Markers and the Development of Peripheral Nerve Pathways}

If a molecule is to be considered as a marker for barrier function, it must, at minimum, be expressed at the right time and place. We therefore examined the spatial and temporal patterns of expression of PNA binding and C-6-S epitopes prior to and during the outgrowth of axons from the spinal cord to the hindlimb. We have focused on these markers because, of the various probes screened in this study (see Materials and Methods), only these two were selectively expressed in all barrier tissues during early motor outgrowth.

We found preferential PNA binding and C-6-S immunoreactivity in the posterior half of each epithelial somite before the outgrowth of motor axons and before the onset of neural crest migration. PNA binding sites and C-6-S immunoreactivity were detected around posterior cells within the cores of recently segmented epithelial somites (Figs. 1A and 1B). These epitopes were not detected in the somitic epithelium itself or in the core cells in the anterior halves of somites. This differential binding pattern was detected in somites just two segments anterior to the segmental plate. Since neural crest cells invade the anterior half of each somite only after dispersal of the epithelial somite (approximately 5 somites anterior to the segmental plate; Loring and Erickson, 1987), and since motor axons enter the somite somewhat later (approximately 10-15 somites anterior to the segmental plate; Tosney, 1988), the asymmetric expression of PNA binding sites and C-6-S develops early enough to mediate the exclusion of both crest cells and motor axons from the posterior half somite. These findings are contrary to those of Stern and colleagues, who were unable to detect an asymmetry of PNA binding during stages relevant to neural crest migration (Davies et al., 1990), but are in agreement with a recent report by Newgreen et al. (1990) on the pattern of C-6-S expression in early somites. Two factors are likely to have contributed to the differences between our results and those of Davies et al. (1990); the preservation and detection of PNA binding sites in our studies was markedly enhanced by the inclusion of $\mathrm{CPC}$ in the fixative and by the use of antibodies to PNA.

Following the dispersal of epithelial somites into a mesenchymal sclerotome and epithelial dermamyotome, both carbohydrate epitopes are preferentially expressed in the sclerotomal portion of each posterior half somite. PNA binding sites and C-6-S immunoreactivity were detected in the posterior sclerotome during the earliest stages of motor axon outgrowth. In contrast, neither epitope was detected in the adjacent anterior sclerotome (Figs. 1C-1E). The expression of PNA binding sites and C-6-S epitopes in the posterior sclerotome thus distinguishes this known functional barrier to axon advance from an adjacent axon pathway, the anterior sclerotome.

Although both carbohydrate epitopes are preferentially expressed in the posterior sclerotome in the chick, the posterior sclerotome of the quail embryo has recently been shown to lack PNA binding sites and the relevance of these sites to the patterning of motor axons and neural crest cells has been questioned (Asamato et $a l ., 1990)$. We confirm the absence of PNA binding in the posterior sclerotome of the quail embryo (not shown). However, we did find that C-6-S immunoreactivity is preferentially expressed in the posterior sclerotome of quail embryos during early stages (Fig. 1F). Thus, the quail embryo does express an asymmetric molecular distribution in the posterior sclerotome that is correlated with the exclusion of motor axons and neural crest cells.

We also found that the perinotochordal mesenchyme in the anterior as well as the posterior half of each segment expresses both PNA binding sites and C-6-S immunoreactivity. Both epitopes were detected in the perinotochordal mesenchyme during the early stages of motor outgrowth (stage 19 at the hindlimb level). PNA binding in the anterior half of each segment was specifically limited to the mesenchyme and extracellular matrix surrounding the notocord and did not include the prospective spinal nerve pathway or the more dorsal anterior sclerotome. Motor axons ramify extensively throughout the dorsal anterior sclerotome, which does not bind the lectin (Figs. 2A-2B). More laterally, the dorsal anterior sclerotome is a narrow zone between the developing myotome and the perinotochordal mesenchyme (Figs. 2A-2B and 3C-3D). Axons are confined to this narrow zone, which is devoid of PNA binding. No axons were found to ramify within the perinotochordal mesenchyme. In contrast, PNA binding in the posterior half of each segment extended further dorsal and lateral to include the entire sclerotome (Fig. 2C). C-6-S immunoreactivity had a similar distribution in both chick and quail embryos (Figs. 2E-2F). However, expression was strongest in the more medial perinotochordal region 

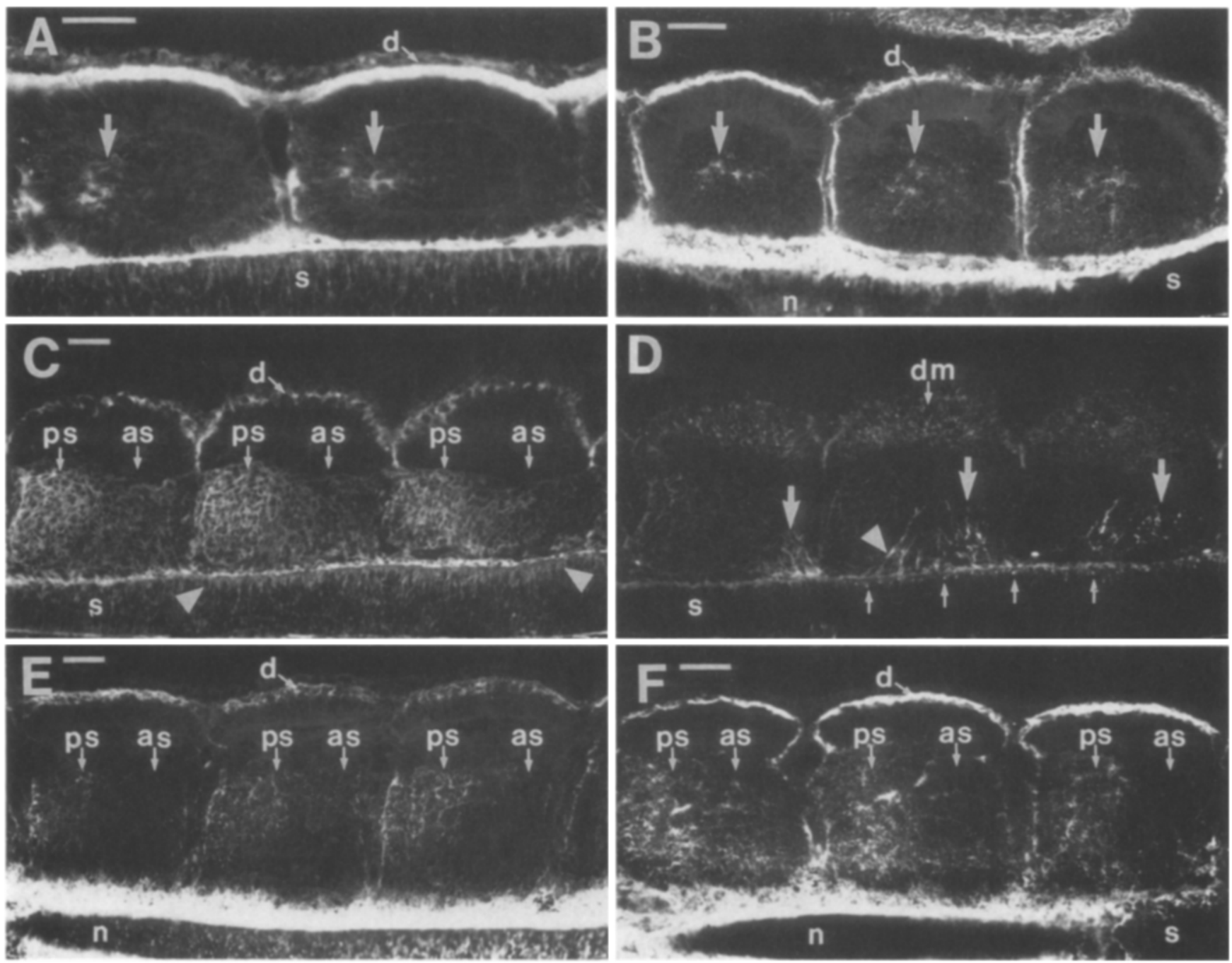

Fig. 1. PNA binding and C-6-S expression are shown in frontal sections of somites near the level of the ventral roots before (A, B) and during (C-F) motor axon outgrowth. Anterior is to the right. (A) PNA differentially binds within the posterior halves (arrows) of recently segmented somites prior to neural crest or axon invasion. The youngest somite, at left, is located two somites anterior to the segmental plate; the earliest detectable motor outgrowth in this stage 17 embryo was nine more segments toward the anterior. (B) C-6-S immunoreactivity is also differentially expressed within the posterior halves (arrows) of epithelial somites. The somite on the left is located three somites anterior to the segmental plate in this stage 16 embryo. Both epitopes are limited to mesenchymal populations within the posterior core of somites; neither epitope is detected within the epithelial portion of somites. (C, D) The same section from the thoracic level of a stage 17 embryo, a level where axons have begun to traverse the sclerotome. (C) PNA binds the posterior (ps) but not the anterior (as) sclerotome during early motor outgrowth. Also note PNA binding within the spinal cord at the level of the ventral roots (between arrowheads). (D) Axons (arrows) are revealed here and in subsequent figures using antibody 6-11-B1 which recognizes acetylated $\alpha$-tubulin; this antibody also displays punctate label within the dermamyotome (dm). Axons traverse only the PNA-negative, anterior sclerotome; axons that initially exit the spinal cord opposite the posterior sclerotome (e.g., arrowhead) turn to avoid the PNA binding regions. Unlike motor axons, commissural axons (small arrows in D) traverse a path within the lateral margin in the spinal cord (s) which expresses PNA binding sites (between arrowheads in C). (E, F) C-6-S immunoreactivity is also detected in the posterior ( $p s)$ but not anterior (as) sclerotome during early motor outgrowth in chick (E) and quail (F) embryos (thoracic level, stage 17). Both PNA binding sites and C-6-S are also expressed around the notochord ( $\mathrm{n}$ in $\mathrm{B}, \mathrm{E}, \mathrm{F})$ and in the predermal space ( $\mathrm{d}$ in $\mathrm{A}, \mathrm{B}, \mathrm{C}, \mathrm{E}, \mathrm{F}$ ) between the ectoderm and the dermamyotome. These and all subsequent figures are fluorescence micrographs of frozen sections. s, spinal cord. Calibration bars $=50 \mu \mathrm{m}$.

and did not extend as far lateral as PNA binding. Moreover, C-6-S is expressed within the notochord, which was consistently PNA-negative at all stages studied (also compare Figs. 5A and 5E).

Thus, the spinal nerve pathway through the sclerotome can be defined by the absence of staining with ei- ther PNA or C-6-S-specific antibodies. The pattern of expression of these epitopes in the sclerotome is therefore strongly correlated with barrier function; both epitopes are preferentially expressed in barrier regions of the sclerotome (posterior sclerotome and perinotochordal mesenchyme) but are not detected in the axon path- 

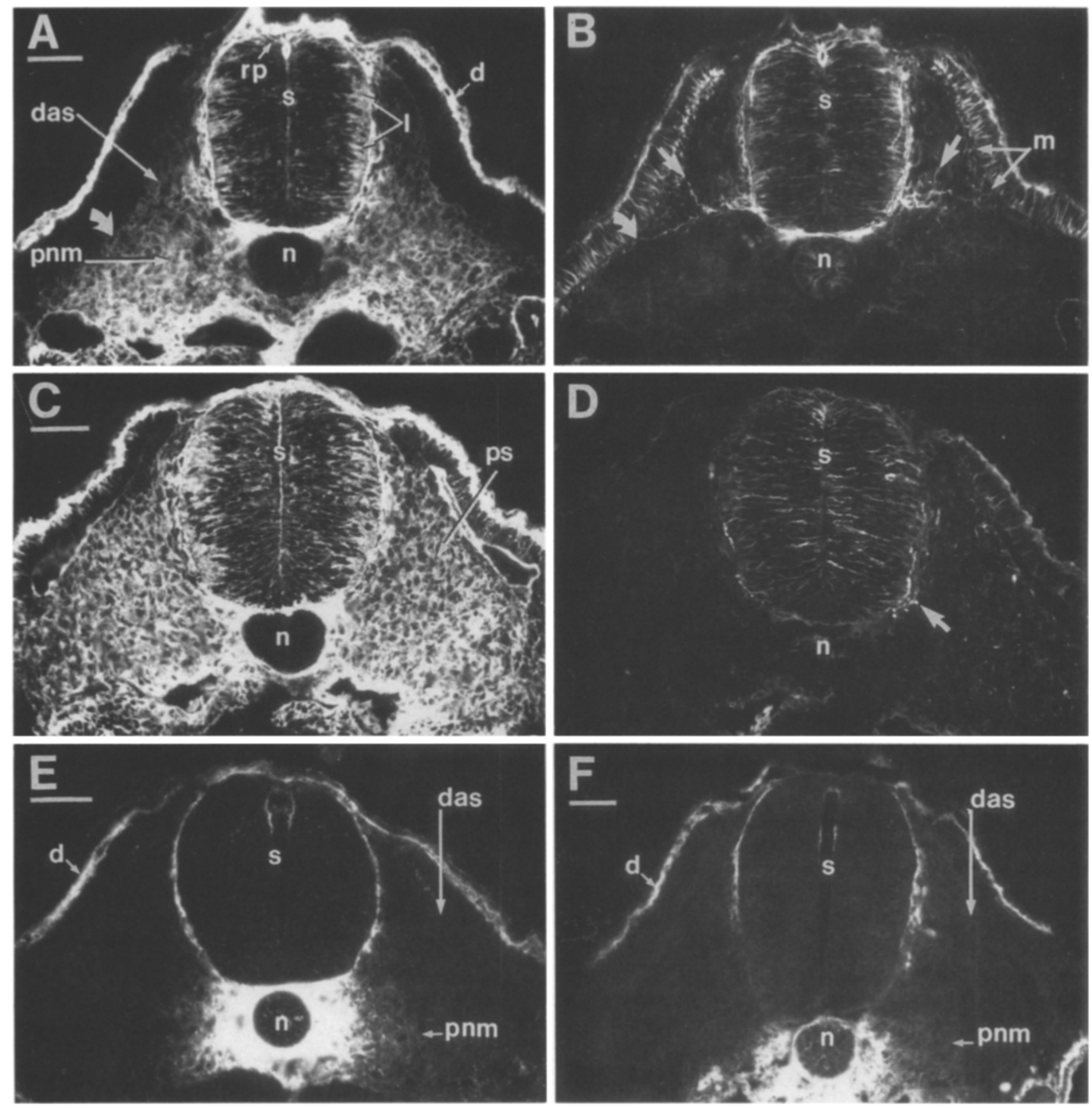

Fig. 2. PNA binding (A, C) and C-6-S immunoreactivity (E,F) during early motor outgrowth are shown in traverse sections through somites at hindlimb levels of stage 19 embryos. (A,B) The same section through the anterior portion of a somite. (A) PNA binds to the perinotochordal mesenchyme (pnm) but not to the dorsal anterior sclerotome (das) which acts as a pathway for axons. PNA also binds the roof plate (rp) and lateral margins (l) of the spinal cord as well as the predermal space (d). (B) Motor axons (arrows) extending toward the myotome (m) ramify widely in the PNA-negative dorsal anterior sclerotome. A distally directed motor axon (curved arrow) projects along the narrow, PNA-negative, distal portion of the dorsal anterior sclerotome (curved arrow in A). (C, D) The same section through the posterior portion of a somite. (C) PNA binding in the posterior sclerotome (ps) is not confined to the perinotochordal region, it extends more dorsally and laterally to include the entire sclerotome (compare to A). (D) Motor axons have turned along the anterior/posterior axis to avoid the posterior sclerotome after leaving the spinal cord and are cut in cross section (arrow). (E, F) Comparison of C-6-S immunoreactivity in the anterior halves of somites from chick (E) and quail (F) embryos. In both species, C-6-S immunoreactivity is not detected in dorsal anterior sclerotome (das) and is differentially expressed in the perinotochordal mesenchyme ( $\mathrm{pnm}$ ) and in the predermal space (d). However, the C-6-S immunoreactivity within these tissues is less spatially extensive than is the PNA binding (compare to A). n, notochord; s, spinal cord. Calibration bars $=50 \mu \mathrm{m}$. 

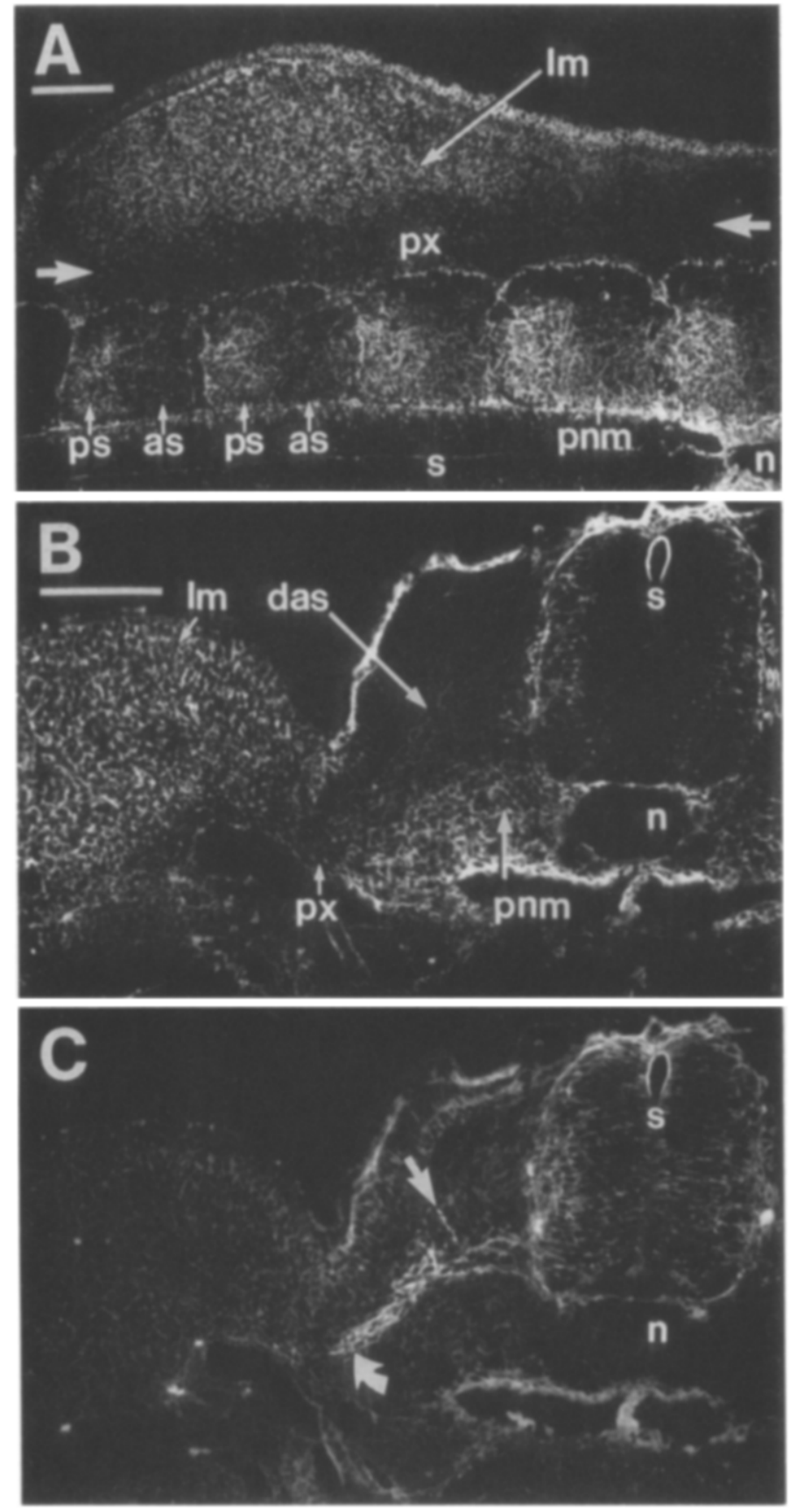

Fig. 3. The plexus region of the hindlimb, an unsegmented axonal pathway, does not bind PNA. (A) This frontal section is of a stage 18 embryo, before the plexus is invaded by the first motor axons. PNA binds the posterior sclerotome (ps) of each somite and uniformly binds the limb bud mesenchyme (lm) but does not bind the anterior sclerotome (as) or the plexus region ( $\mathrm{px}$ ) that extends along the entire base of the limb (between arrows). The section is oblique and shows the notochord $(\mathrm{n})$ and perinotochordal mesenchyme $(\mathrm{pnm})$ toward the anterior (at right). (B, C) The same transverse section from the midhindlimb level at stage 20, when axons are first reaching the plexus region. (B) PNA binds the perinotochordal mesenchyme (pnm) and the limb bud mesenchyme ( $\mathrm{lm}$ ) but not the dorsal anterior sclerotome (das) or the plexus mesenchyme (px). (C) Axons (curved arrow) in the spinal nerve are approaching but have not yet colonized the plexus region. Also note axons (arrow) in the dorsal anterior sclerotome and way. Moreover, these carbohydrate epitopes are expressed before and during the period when these barrier regions are avoided by motor growth cones.

After traversing the sclerotome, the spinal nerves converge at the base of the limb and expand along the anterior-posterior axis to form an unsegmented plexus that is characterized by the absence of staining with either PNA- or C-6-S-specific antibodies. We found that the plexus region does not bind PNA even at stages prior to the invasion of this region by the earliest axons. Figure $3 \mathrm{~A}$ illustrates a stage 18 embryo in oblique frontal section during early motor outgrowth and prior to axonal invasion of the plexus region. Although PNA strongly binds to both the posterior sclerotome and the undifferentiated limb bud mesenchyme (see below), the mesenchyme of the plexus region did not bind the lectin. Transverse sections (Figs. 3B-3C) also illustrate PNA binding within the perinotochordal mesenchyme but not in the plexus mesenchyme as the first axons approach the plexus region. The unsegmented character of the plexus mesenchyme is therefore correlated with the absence of PNA binding and the spatial expansion of axonal pathways.

The mesenchyme that constitutes the presumptive pelvic girdle also expresses both PNA binding sites and C-6-S immunoreactivity, whereas these epitopes are not detected in the pathways that transmit axons from the plexus to the limb through the girdle region. This correlation is best appreciated by comparing the patterns of preferential PNA binding in cross sections from different axial levels, since axons extend into the limb as two major nerve trunks in the crural (anterior) and sciatic (posterior) regions but do not traverse the central girdle region at the midthigh level unless the girdle mesenchyme is surgically deleted (Tosney and Landmesser, 1984, 1985). At the midthigh level, we detected preferential PNA binding and C-6-S immunoreactivity in the prospective girdle mesenchyme lateral to the plexus as axons first begin to populate the plexus region (Figs. $4 \mathrm{~A}-4 \mathrm{~B})$. At this axial level, the prospective girdle region distal to the nerve front presents a continuous barrier to axon advance that is characterized by the expression of both carbohydrate epitopes. Axons do not traverse the girdle region at this axial level; they turn in the anterior/posterior axis and extend along the PNA-negative plexus region (Figs. $4 \mathrm{C}-4 \mathrm{D}$ ).

In contrast, in the crural and sciatic regions, axons traverse discontinuities in the girdle mesenchyme that initially express lower levels of PNA binding and C-6-S immunoreactivity; the intensity of staining in these axon pathways then declines as axons invade the limb. The crural region is illustrated in Fig. 5. As axons enter

the absence of axons in the perinotochordal mesenchyme. n, notochord; s, spinal cord. Calibration bars $=100 \mu \mathrm{m}$. 

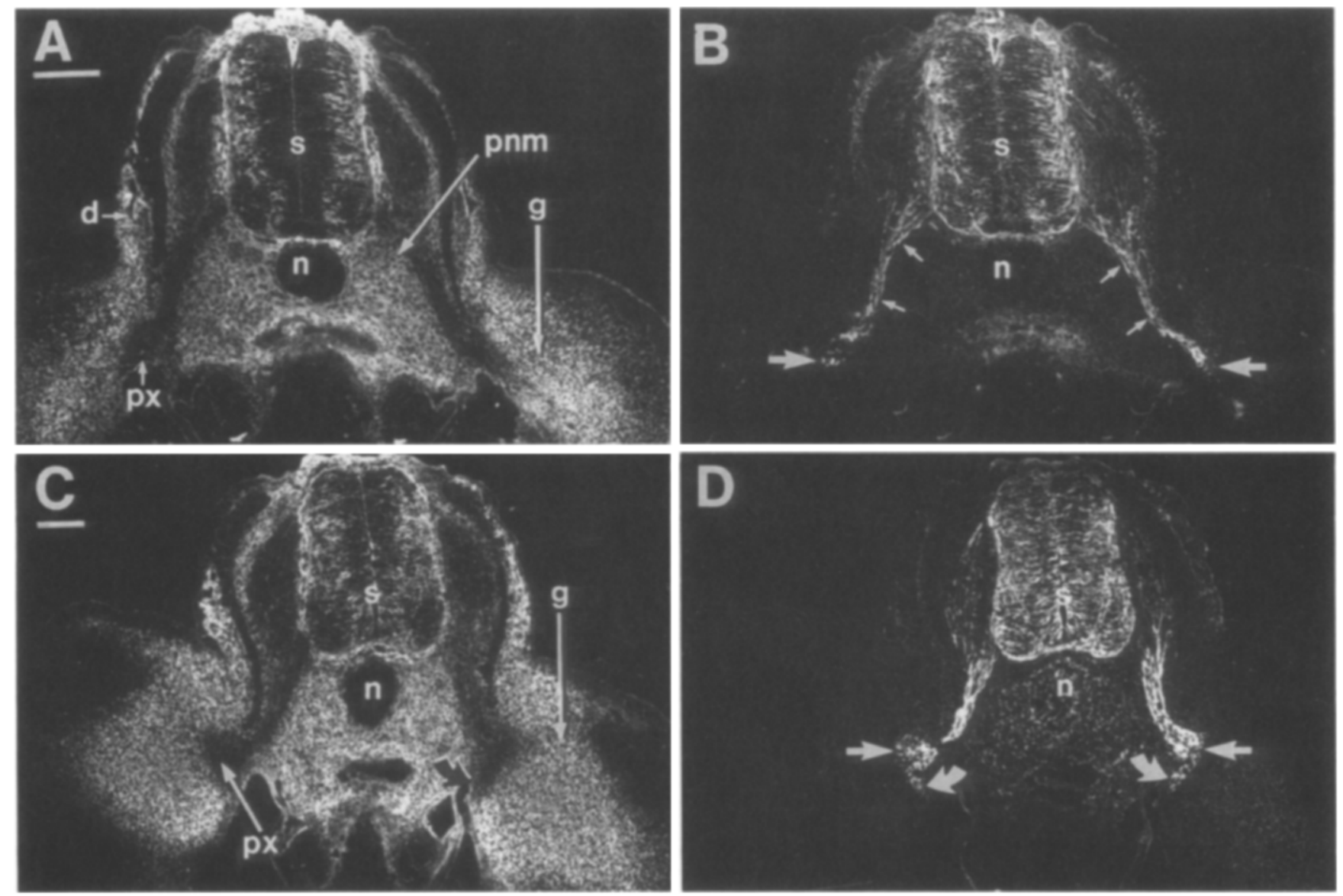

Fig. 4. Transverse sections at the midhindlimb level document patterns of PNA binding to the pelvic girdle precursor which acts as a continuous barrier at this axial level. (A, B) The same section through a stage 22 embryo, after axons have entered the plexus. (A) PNA binding in the proximal limb is now confined to the pelvic girdle precursor $(\mathrm{g})$ and extends along the full dorsal-ventral axis at the limb base. PNA does not bind the plexus region (px) but labels the perinotochordal mesenchyme (pnm) and axial dermis (d) at this stage. (B) Axons in the spinal nerves (small arrows) have colonized the plexus region but turn upon contacting the PNA-positive girdle precursor and are cut in cross section (arrows). (C,D) The same section from a stage 25 embryo; by this stage, axons have penetrated the limb at more anterior (crural) and more posterior (sciatic) levels (see Figs. 5, 6). (C) PNA binding fully delineates the midlimb region of the pelvic girdle precursor (g) and extends along its entire dorsal-ventral axis just distal to the plexus region. The plexus region (px) and the ventral crural nerve trunk nerve pathway (curved black arrow) that lies ventromedial to the girdle do not bind the lectin. (D) Axons traverse only PNA-negative regions; they extend to the base of the limb, turn along the anterior/posterior axis within the plexus (arrows) and within the ventral nerve trunk pathway (curved arrows). $n$, notochord; s, spinal cord. Calibration bars $=100 \mu \mathrm{m}$.

this plexus its distal border is delimited by a relatively homogeneous mesenchyme that strongly binds PNA. Between stage 21 and 23 , a region of low PNA binding emerges between the PNA-positive dorsal and ventral portions of the presumptive girdle (Fig. 5A). During this period, axons begin to extend into the limb and their ultimate course between the girdle elements is marked by this region of low PNA binding (compare Figs. 5A-5B with Figs. 5C-5D). The expression of C-6-S immunoreactivity in the presumptive girdle in this region is essentially similar in both timing and pattern in the chick (Fig. 5E) and quail (not shown). Moreover, PNA strongly labels the presumptive girdle but not the axon pathways in the quail (Fig. $5 \mathrm{~F}$ ). The sciatic region, where axons enter the limb in restricted regions by growing between the presumptive girdle elements and the presumptive femur, displays a similar pattern (Fig. 6). As axons begin to fill this plexus, we detected PNA binding to the girdle elements and the presumptive femur. By stage 23, axons begin to form dorsal and ventral sciatic nerve trunks by branching around the proximal end of the PNA-positive femur (Figs. 6A-6B). The prospective course of these nerves into the limb is delineated by two regions of lower PNA binding between girdle elements and the femur; these two regions are later invaded by axons (compare Figs. 6A-6B with Figs. 6C$6 \mathrm{D})$. The pattern of PNA binding in the sciatic region was identical in chick and quail (not shown). The timing and pattern of C-6-S expression in both chick (Fig. 6E) and quail (not shown) were similar to those of PNA bind- 

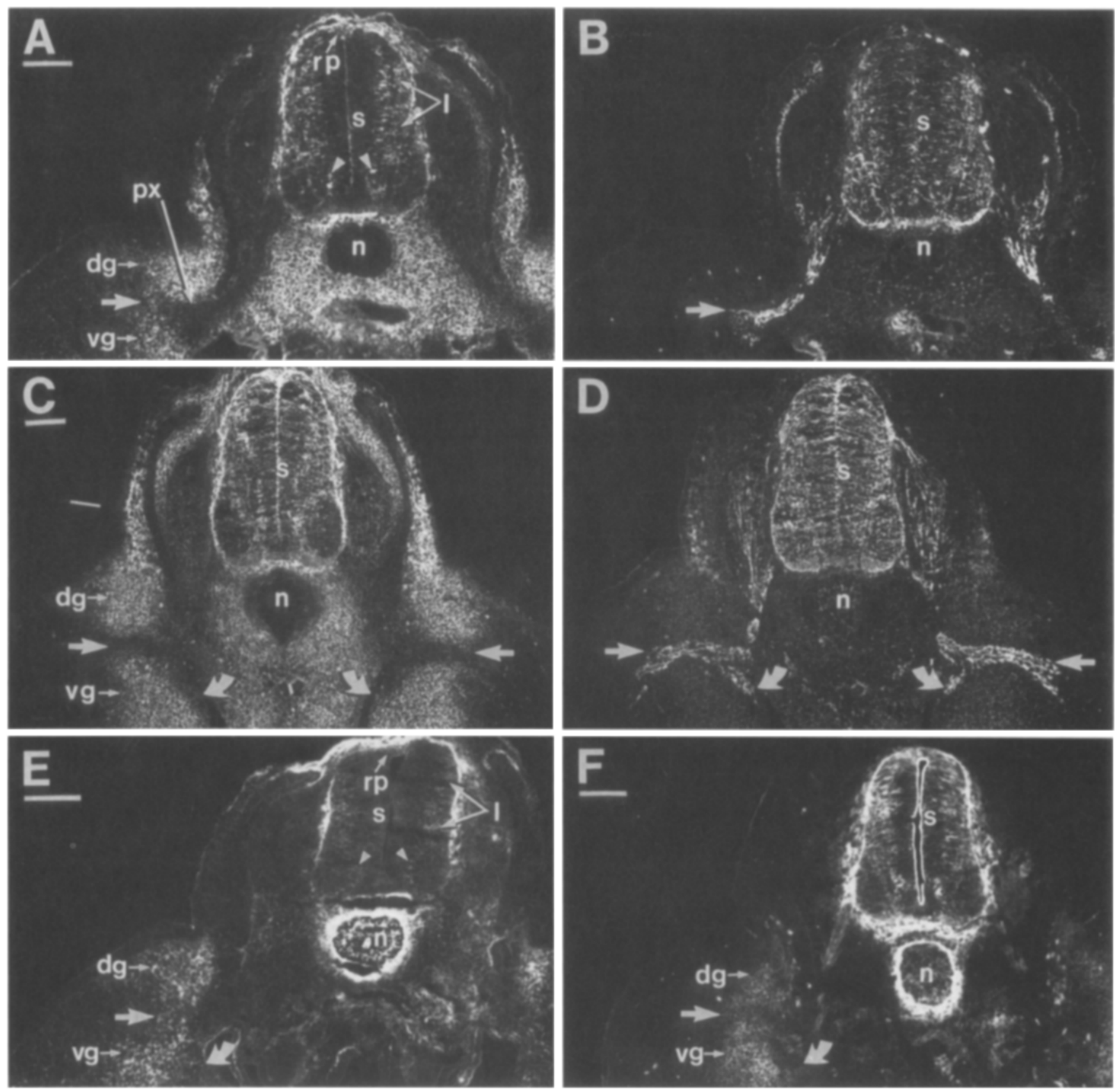

FIG. 5. At the crural axial level illustrated here in transverse sections, axons enter the limb by growing through gaps between developing girdle elements; these gaps express lower levels of PNA binding sites (A, C, F) and C-6-S immunoreactivity (E). (A, B) The same section from a stage 23 chick. (A) PNA binds the dorsal (dg) and ventral (vg) girdle elements; a PNA-negative gap (arrow) in the prospective dorsal crural nerve pathway is less distinct than at later stages but is already detectable between the girdle elements. PNA binding is also absent from the plexus region (px). PNA binding sites continue to be expressed in the roof plate (rp) and lateral margins (l) of the spinal cord (S) and delimit the medial boundaries (arrowheads) of the motor columns. (B) Axons that have begun to extend from the plexus region to the limb are confined to the PNA-negative dorsal nerve pathway (arrow). (C, D) The same section from a stage 25 chick. (C) PNA binds the dorsal (dg) and ventral (vg) girdle elements which surround the PNA-negative dorsal nerve trunk pathway (arrows). PNA binding is also absent from the ventral nerve trunk pathway (curved arrows) which is visible in this section ventromedial to the girdle. (D) Axons of the dorsal (arrows) and ventral (curved arrows) crural nerve trunks extend into the limb through the PNA-negative regions. (E) C-6-S immunoreactivity is also localized to the dorsal (dg) and ventral (vg) girdle elements that surround regions of low expression, the dorsal (arrow) and ventral (curved arrow) crural nerve pathways. Also note label in the lateral margins of the spinal cord (1), in the roof plate ( $r p$ ), and bordering the medial portion of the motor columns (arrowheads; compare to PNA label in Fig. 5A). Stage 23 chick. (F) In the quail embryo, PNA also binds the crural girdle elements (dg, $\mathrm{vg}$ ) in a similar pattern. In particular, regions of lower expression correspond to the incipient dorsal (arrows) and ventral (curved arrows) nerve trunk pathways (stage 23 quail). n, notochord; s, spinal cord. Calibration bars $=100 \mu \mathrm{m}$. 

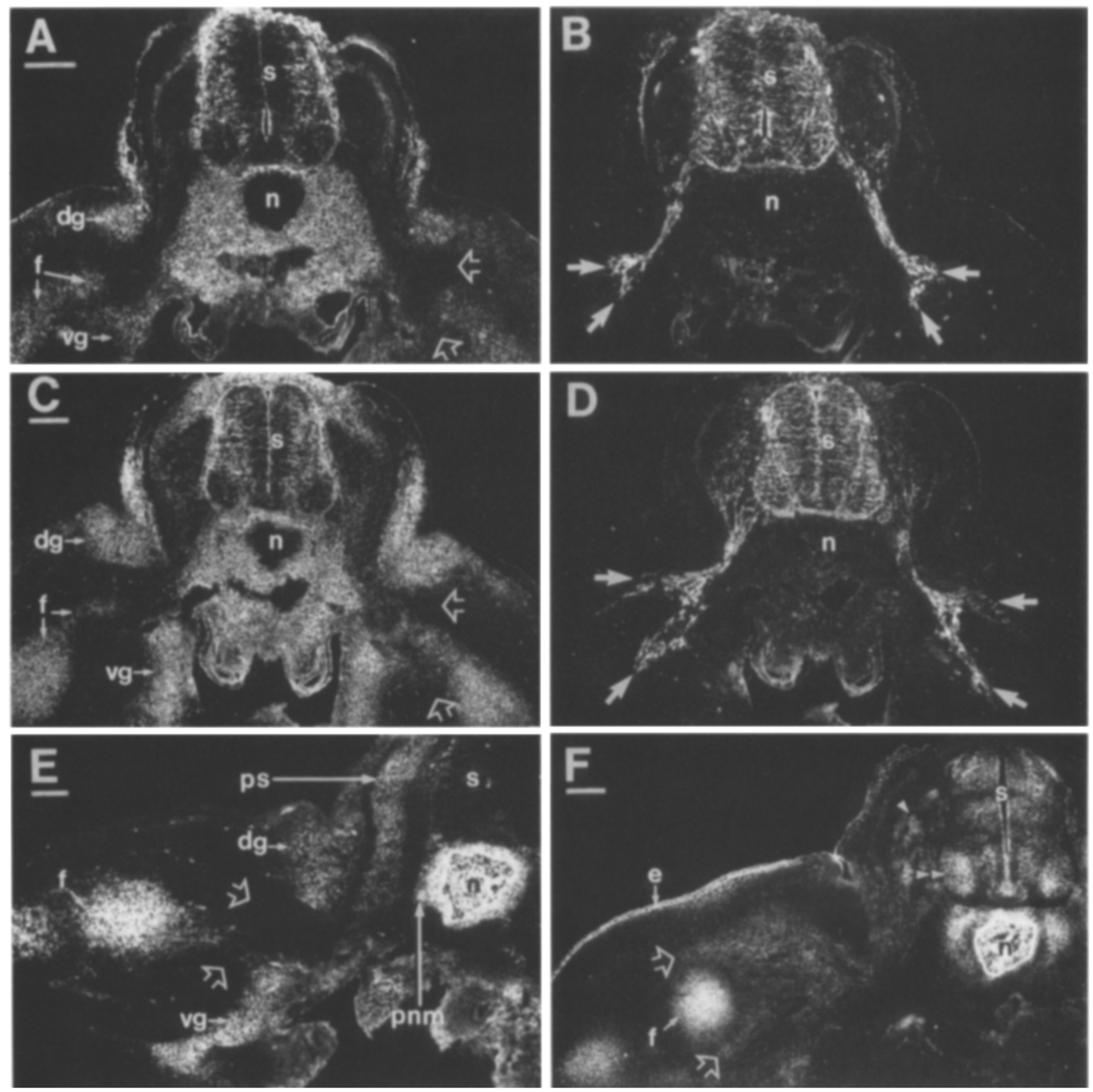

FIG. 6. In the sciatic region illustrated here in transverse sections, axons enter the limb by growing between the developing girdle elements and the presumptive femur; these gaps express lower levels of PNA binding sites (A, C) and C-6-S immunoreactivity (E). (A, B) Comparison of patterns of PNA binding and axon advance in the same section of a stage 23 chick. (A) PNA binds the dorsal (dg) and ventral (vg) girdle elements and the presumptive femur (f). PNA-negative gaps (open arrows) between the girdle elements and the femur mark the prospective paths of the dorsal and ventral sciatic nerve trunks. (B) The nerve trunks (arrows) have begun to branch around the proximal end of the presumptive femur and enter the PNA-negative gaps. (C, D) Comparison of patterns of PNA binding and axon advance in the same section of a stage 25 chick. (C) PNA-negative gaps (open arrows) are prominent between the girdle elements (dg, vg) and the presumptive femur (f). (D) Axons (arrows) in the sciatic nerve trunks branch around the presumptive femur and are transmitted to the limb through the PNA-negative gaps. Note that axons grow around rather than through the PNA-positive presumptive femur. (E) C-6-S immunoreactivity is expressed in the girdle elements (dg, vg) and presumptive femur (f) but is not detected in the sciatic nerve pathways (open arrows) as shown in this section of a stage $25+$ chick. While the pattern is very similar to that of PNA binding (compare to C), C-6-S is consistently expressed to a more limited spatial extent in the perinotochordal mesenchyme (pnm) and is also expressed in the notochord ( $\mathrm{n}$ ). The C-6-S antibody also consistently labels the femur more intensely than the girdle precursor. ps, posterior sclerotome. (F) C-4-S/DS immunoreactivity in the sciatic region. Unlike C-6-S, C-4-6/DS is not detected in the girdle; moreover, it is expressed in the sciatic nerve pathway (open arrows, compare to D and E) as well as in the 
ing. Thus, the prospective nerve pathways through the girdle region are marked by regions that do not stain with PNA- or C-6-S-specific antibodies.

\section{PNA Binding in the Absence of Axon Outgrowth}

Since the decline in PNA binding and C-6-S immunoreactivity is essentially coordinate with the accumulation of growth cones in the plexus region and their extension toward the limb, the pattern of staining with these probes could be dependent on the presence of growth cones. For example, extracellular materials could be differentially digested in these regions by proteases, which are known to be released from growth cones (Kryostosek and Seeds, 1981; Pittman, 1985). Alternatively, the absence of staining with PNA and C-6$\mathrm{S}$-specific antibodies in the presumptive axon pathways may be independent of growth cone invasion, which would strongly suggest the evolution of a preformed pathway bounded by barriers to axon advance. To distinguish between these alternatives, we examined the pattern of PNA binding following unilateral neural tube deletions. We used PNA because it was possible to label both axons and barrier tissues in the same sections. This enabled us to precisely evaluate the extent of the deletion as well as to determine the pattern of barrier marker expression.

We found that the preferential distribution of PNA binding in barrier tissues but not in axon pathways is independent of axon outgrowth. Figure 7 illustrates the pattern of PNA binding at the level of the crural nerve trunk in operated embryos at various stages of development. PNA specifically bound to the perinotochordal mesenchyme and the early (stage 22) girdle mesenchyme but not to the spinal nerve pathway or plexus region even in experimental embryos without any detectable axons in the relevant segments (Figs. 7A-7B). Moreover, the PNA-negative gaps in the girdle mesenchyme that delineate both the dorsal and the ventral crural pathways developed on schedule even in the complete absence of motor outgrowth and the virtual absence of sensory outgrowth (Figs. 7C-F). We also determined that there was no significant difference in the overall size of the dorsal crural nerve pathway in operated limbs by measuring the anterior-posterior extent of the PNA-negative gap in both limbs of stage 25-26 neural tube-deleted embryos. This nerve pathway constituted $19 \%( \pm 7.5 \%)$ of the anterior-posterior extent of control limbs and $17 \%( \pm 6 \%)$ of the anterior-posterior extent of experimental limbs. Therefore, it is unlikely that axons enlarge a small preexisting pathway. These results strongly suggest that the lack of PNA binding in axon pathways is an independent property of the mesenchyme within these pathways and is not dependent on an interaction with growth cones or on the presence of axons in the tissue sections.

\section{PNA Binding and C-6-S Expression in the Limb Bud}

At stages prior to axon invasion, the limb bud transiently expresses inhibitory properties. Motor neurons do not extend axons when cultured on slices of early limb buds (stage 18-22), but will extend axons on slices of older limbs (Landmesser, 1988). Moreover, axons will not enter a young limb bud transplanted to an older host until the graft matures (Swanson and Lewis, 1982). To determine whether this transient inhospitible period is correlated with the transient expression of markers for barrier function, we examined the pattern of PNA binding and C-6-S expression at various stages of limb development.

The early limb bud transiently exhibits a uniform pattern of PNA binding and C-6-S immunoreactivity. Between stages 18 and 21 (Figs. 3A, 8A-8B) the expression of both carbohydrate epitopes is essentially homogeneous with little regional differentiation. As the limb matures, both epitopes become largely localized to the prechondrogenic region in the core of the limb, which is distinctly stained by stage 22 (Figs. 8C - 8D). The limb regions comprising the prospective nerve pathways and the muscle masses are delineated by the absence of staining with either PNA- or C-6-S-specific antibodies as early as stage 22 . Thus, staining with both probes is largely confined to the precondrogenic core prior to the axon invasion of the hindlimb (stage 24). The transient period of uniform expression of these carbohydrate epitopes in the early limb bud therefore correlates with the period during which the limb bud is hostile to motor growth cone advance.

\section{Comparison of Various Markers for Chondrogenic Development}

Since PNA binding molecules and chondroitin sulfate proteoglycans are typical of chondrogenic differentiation (Kimata et al., 1986; Aulthouse and Solursh, 1987), we also examined the expression of other cartilage proteoglycan epitopes to determine if they are preferentially expressed in barrier tissues during axon outgrowth. Monoclonal antibodies to chondroitin-4-sulfate/dermatan sulfate (C-4-S/DS) and keratan sulfate (KS) did not label all barrier tissues during axon outgrowth. For example, C-4-S/DS immunoreactivity was detected in the perinotochordal mesenchyme, limb core, 

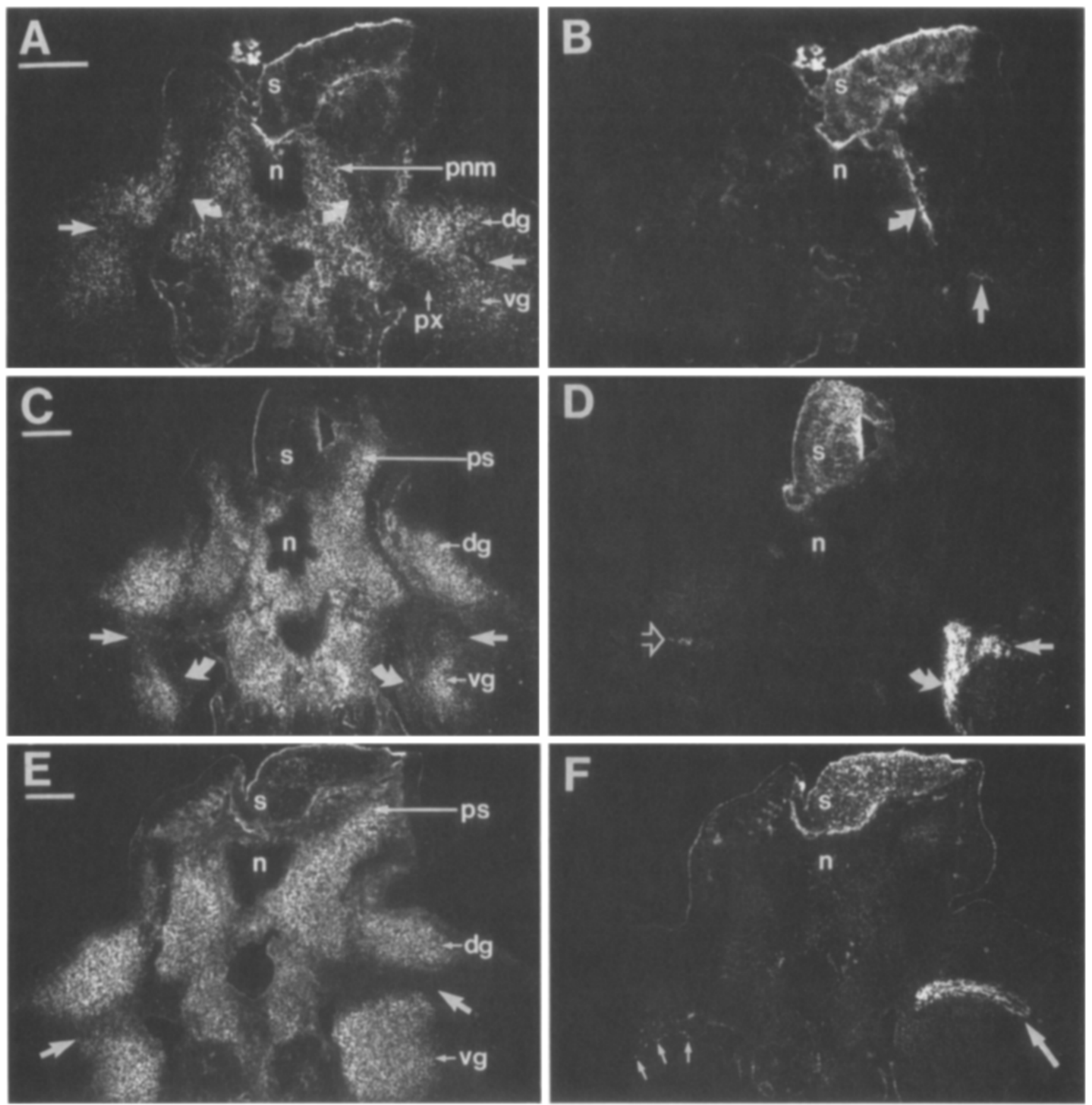

FIG. 7. The development of PNA-negative nerve pathways is independent of axon outgrowth as shown by transverse sections of embryos in which the left half of the spinal cord (s) has been deleted. (A, B) The same transverse section from the crural region of a stage $22+$ embryo that had no detectable axon outgrowth on the experimental side. (A) PNA binds the perinotochordal mesenchyme (pnm) and the dorsal (dg) and ventral (vg) girdle elements but not the spinal nerve pathway (curved arrows) or plexus region (px) on both the control and the operated (left) side. PNA-negative gaps (arrows) between girdle elements have begun to form on both sides. (B) On the operated (left) side of this embryo, no axons were detected in this or the two adjacent segments. On the control (right) side, axons in the spinal nerve (curved arrow) have projected as far as the plexus region (arrow). (C, D) The same transverse section through the anterior crural region of a stage 25+ embryo with complete motor deletion and substantial sensory deletion on the operated side. (C) PNA binds the posterior sclerotome (ps) and girdle elements (dg, vg) but not the dorsal (arrows) or ventral (curved arrows) crural nerve pathways. Note that the size of the PNA-negative pathways is clearly normal despite the reduction of axon outgrowth. (D) Axons on the control side have colonized the dorsal (arrow) and ventral (curved arrow) crural pathways, but no axons were detected in the ventral crural pathway on the operated (left) side. A few sensory axons remain in the left dorsal crural pathway (open arrow). (E, F) The same transverse section through a more posterior portion of the crural region from a stage $25+$ embryo in which only a small population of sensory axons developed on the operated side. (E) PNA binds the posterior sclerotome (ps) and girdle elements (dg, vg) that demarcate the PNA-negative dorsal crural nerve pathways (arrows) on both the operated (left) and control (right) sides. (F) On the operated (left) side, a small contingent of sensory axons has turned upon contact with the girdle (small arrows) and has 
spinal cord, DRG, and ectoderm but was not detected in the posterior sclerotome or in the girdle mesenchyme during early axon outgrowth. Moreover, apparently lower levels of C-4-S/DS expression were also detected within axon pathways (Fig. 6F). KS immunoreactivity was only detected in and immediately adjacent to the notochord (not shown). Since KS immunoreactivity was not detected in barrier tissues with $\mathrm{C}-6-\mathrm{S}$ immunoreactivity, it is unlikely that the C-6-S antibody is binding exclusively to the large aggregating proteoglycan of cartilage, which bears both epitopes (see Ruoslahti, 1988 for review). Thus, KS and C-4-S/DS are not selective markers for barrier tissues during early axon outgrowth.

Although PNA binding sites and C-6-S immunoreactivity are expressed in similar spatial and temporal patterns in avian embryos, these patterns are clearly not identical. The differences are especially apparent in the developing limb bud (Fig. 8); PNA strongly labels the ectoderm and its basement membrane at all stages of development, whereas, C-6-S antibodies do not label these structures. Similarly, PNA discretely labels the prechondrogenic core of the limb at stage 22 , whereas C-6-S immunoreactivity is more widely dispersed. We also observed consistent regional differences in staining intensity within structures that were labeled by both probes (compare Figs. $8 \mathrm{E}$ and $8 \mathrm{~F}$ ). Our results therefore suggest that the two barrier markers we have identified are not recognizing the same molecule.

\section{PNA Binding and C-6-S Expression in the Developing Spinal Cord}

We also found that both PNA binding sites and C-6-S immunoreactivity are expressed in specific patterns in the developing spinal cord. Strong PNA binding was detected in the roof plate and along the lateral margin of the spinal cord as early as stage 19 (Fig. $2 \mathrm{~A}$, also see Figs. 1C-1D). As the spinal cord matured and the lateral motor columns became distinct, PNA binding within the ventral spinal cord delimits the medial border of the motor columns, which were consistently PNA-negative (Fig. 5A). This pattern of binding was apparent at all subsequent stages examined. Although C-6-Simmunoreactivity was difficult to preserve in the spinal cord, in well preserved specimens its distribution was identical to that of PNA (compare Figs. 5A and 5E). These results indicate that PNA binding and C-6-S epitopes are expressed in the roof plate of the early chick spinal cord, a structure that is a putative barrier to axon advance across the dorsal midline in the early rat embryo (Snow et al., 1990a).

\section{DISCUSSION}

\section{PNA and Chondroitin-6-sulfate Are Markers for Barriers to Axon Advance}

We have identified two carbohydrate epitopes that are preferentially expressed in three tissues that have been experimentally shown to share a similar axon guidance function in the chick embryo; the pelvic girdle precursor, the posterior sclerotome, and the perinotochordal mesenchyme all provide guidance cues that result in growth cone avoidance and thereby act as barriers to axon advance (Tosney and Landmesser, 1984; Keynes and Stern, 1984; Stern and Keynes, 1987; Tosney, 1988; Tosney and Oakley, 1990). We have shown here that all three of these tissues express both PNA binding sites and C-6-S immunoreactivity as growth cones interact with and avoid these barrier tissues. Previous studies had shown that PNA binding sites (Stern et al., 1986) and chondroitin sulfate proteoglycans (Tan et al., 1987; Newgreen et al., 1990) are preferentially expressed in the posterior sclerotome. We have extended these findings by showing that these carbohydrate epitopes are selectively expressed in all three barrier tissues during the earliest phases of peripheral axon outgrowth. Moreover, we have shown that these epitopes distinguish functional barriers to axon advance from prospective axon pathways within an otherwise largely homogeneous mesenchyme.

The strong spatial and temporal correlation between experimentally defined barrier function and the expression of PNA binding sites and C-6-S immunoreactivity suggests that molecules bearing these epitopes are potential mediators of barrier function. However, since any causal relation between the expression of these epitopes and barrier function remains to be established, we conservatively propose that these epitopes are at least reliable molecular markers for barriers to axon advance.

The utility of these markers for identifying axon barriers is further demonstrated by our observation that both markers are uniformly expressed in the early limb bud mesenchyme, during the period when it may act as a transient barrier to axon advance. In vitro studies using living slices of chick embryos have shown that the early limb bud (stages 18-22) presents a hostile environment for motor axon outgrowth (Landmesser, 1988). In addition, heterochronic transplantation of limb buds has shown that the timing of axon invasion is determined by the maturity of the limb rather than by intrinsic properties of the invading growth cones (Swanson and Lewis, 1982). We have shown that during this

independently navigated the dorsal crural nerve pathway to extend as far distally as the axons (arrow) on the control (right) side. n, notochord; $\mathrm{s}$, spinal cord. Calibration bars $=100 \mu \mathrm{m}$. 

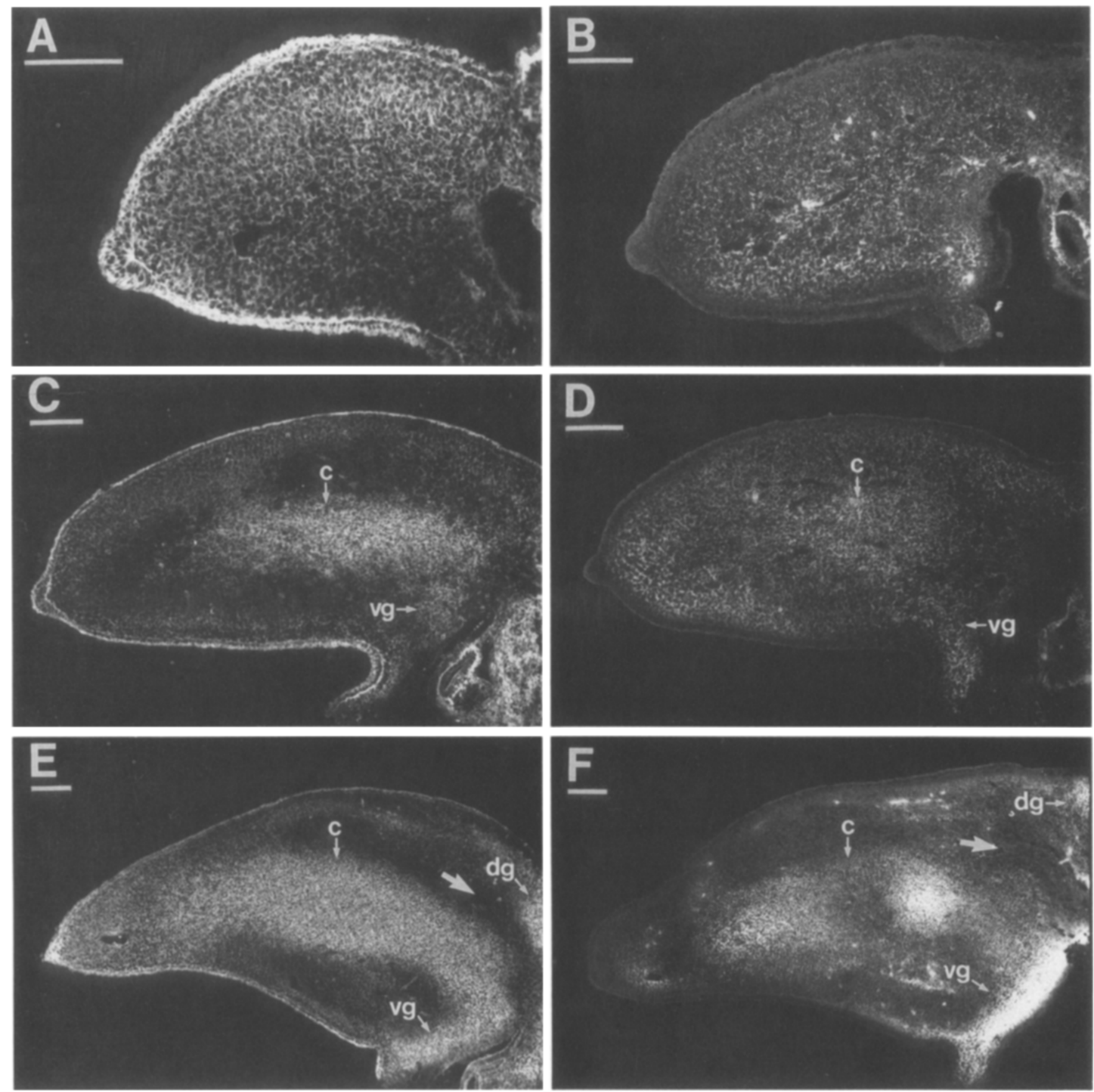

FIG. 8. PNA binding and C-6-S staining within the chick hindlimb are gradually restricted to the prechondrogenic core. (A, C, E) PNA binding and (B, D, F) C-6-S immunoreactivity at matched stages of limb development using transverse sections from the midhindlimb level. Distal is to the left. (A, B) During early stages when the limb bud presents a hostile environment for motor axon outgrowth, the distribution of PNA binding sites and C-6-S immunoreactivity is largely uniform in the limb. Stage 19 embryos. (C, D) During the period when axons are colonizing the plexus region proximal to the girdle, PNA binding and C-6-S staining gradually become largely restricted to the prechondrogenic core of the limb (c) and to the presumptive girdle (vg; dorsal girdle is not shown). Stage 22 embryos. (E, F) By stage 25, as axons enter the limb proper, PNA binding sites and C-6-S staining are confined to the limb core (c), presumptive girdle elements (dg, vg), and the distal tip of the limb bud. Neither epitope is detected in axon pathways; only the dorsal nerve pathway (arrows) is visible in these sections. Note that the two epitopes are distributed in a similar but nonidentical pattern at all stages. For instance, PNA consistently binds more to dorsal than to ventral mesenchyme in the early limb (A) and later it more sharply delineates the limb core (C, E). Also note that PNA strongly labels the ectoderm and underlying basement membrane whereas C-6-S antibodies do not. Calibration bars $=100 \mu \mathrm{m}$. 
hostile period both PNA binding sites and C-6-S immunoreactivity are uniformly expressed throughout the limb bud, again documenting a correlation between specific carbohydrate expression and barrier function. We have also shown that axons normally invade the limb only after the expression of these epitopes becomes largely restricted to the prechondrogenic core of the limb, another region avoided by invading axons.

Our results further suggest that the cellular and molecular mechanisms that mediate the segmental patterning of axons within the somites may also mediate the general guidance of axons in other regions of the embryo. The segmental patterning of axons is dependent on the sclerotome and represents a striking example of axon guidance by general guidance cues; all subpopulations of sensory and motor axons respond similarly by avoiding the posterior sclerotome and the specific deployment of motor axons is independent of segmental patterning (Tosney, 1988a). The response of axons to the perinotochordal mesenchyme and pelvic girdle precursor is identical on a functional level in that all subpopulations also avoid these tissues. The fact that these tissues all share both functional and molecular similarities suggests that the guidance mechanisms may be the same in all cases (see Tosney and Oakley, 1990).

\section{Patterned Expression of Barrier Markers in Neural Tube-Deleted Embryos}

The pattern of normal development suggested that growth cones might actively participate in the formation of PNA-negative pathways through the girdle region since these pathways are not clearly delineated prior to axonal invasion. However, PNA-negative pathways developed, on schedule, even in the virtual absence of axon outgrowth. We can therefore rule out several possible explanations for the preferential expression of specific carbohydrate epitopes in barrier tissues but not in axon pathways. First, this pattern of expression is not merely due to the presence of nonstaining axons within the pathways; the surgical elimination of the vast majority of peripheral axons did not alter the size or distribution of PNA-negative pathways. Second, it is highly unlikely that the absence of barrier markers in pathways is due to differential digestion by proteases released from growth cones, since PNA-negative pathways of normal size and position developed even when no axons could be detected within the relevant segments. These results also argue that an interaction between growth cones and pathway mesenchyme is insufficient to explain the differential expression patterns reported here. We therefore conclude that barriers are distinct from axon pathways at the molecular level.
A molecular distinction between paths and barriers is also supported by studies that have identified unique cellular and molecular features which distinguish axon pathways. Presumptive peripheral axon pathways are characterized by widespread cell death and phagocytosis (Tosney et al., 1988), the expression of butyrlcholinesterase activity (Layer et al., 1988), and the expression of a $70-\mathrm{kDa}$ membrane protein (Tanaka et al., 1989). In all cases these features have been found to be independent of axon outgrowth. We have documented another distinguishing feature of axon pathways; the absence of barrier markers, which is an independent characteristic of the cells that comprise these pathways.

\section{Barrier Function and Neural Crest Migration}

Neural crest cell migration may be constrained by the same tissues that act as barriers to axon advance. For example, crest cells, like motor axons, invade the anterior but not the posterior sclerotome (Rickmann et al., 1985; Bronner-Fraser, 1986; Loring and Erickson, 1987) and avoid both the perinotochordal mesenchyme (Newgreen et al., 1986) and the pelvic girdle precursor (Erickson, Oakley, and Tosney, unpublished observations).

Are the markers we have identified also reliable markers for barriers to neural crest cell migration? A recent study (Davies et al., 1990) in fact suggested that the differential expression of PNA binding sites in the posterior sclerotome develops too late to be relevant to the patterned migration of crest cells through the somite. Similarly, Perris and colleagues have recently shown that chondroitin sulfate/keratan sulfate proteoglycans are preferentially expressed in the posterior sclerotome after neural crest cells have colonized the anterior sclerotome (Perris et al., 1991). We have shown here that both PNA binding sites and C-6-S immunoreactivity are expressed in the posterior halves of early epithelial somites; both epitopes are therefore expressed asymmetrically prior to the preferential colonization of the anterior sclerotome by the earliest migrating neural crest cells (see Loring and Erickson, 1987; Teillet et al., 1987). We have recently confirmed the relationship between the expression of PNA binding sites and the timing of neural crest migration through the somite by double labeling with HNK-1 (Schroeter et al., 1990). On the basis of the early differential expression of PNA binding sites and C-6-S immunoreactivity in the posterior somite, we suggest that these epitopes are also reliable markers for barriers to neural crest migration.

If these epitopes are markers for barriers to neural crest migration, how can we account for the expression of both markers in the prospective premelanocyte pathway between the dermamyotome and the ectoderm? Our preliminary results using PNA and HNK-1 indicate that barrier markers are expressed transiently in the 
premelanocyte pathway and that neural crest cells enter this pathway only after a diminution of PNA binding (Schroeter et al., 1990). Moreover, since the surgical deletion of the dermamyotome eliminates barrier marker expression and permits the precocious invasion of the premelanocyte pathway (Lasky et al., 1991), this pathway may indeed present a transient barrier to neural crest migration.

\section{Axons Avoid Prechondrogenic Tissues}

The avoidance of barrier tissues by axons and neural crest cells may be related to the common developmental fate shared by these tissues; the posterior sclerotome, perinotochordal mesenchyme, and pelvic girdle precursor all differentiate into cartilage and eventually form bone. Although the anterior sclerotome also contributes to boney structures (Stern and Keynes, 1987), the relative contributions of the perinotochordal (barrier) region and the more dorsal anterior sclerotome (pathway) to the formation of boney structures have not been clearly defined. Moreover, the results of both descriptive and experimental studies suggest that the vertebral bodies are derived from the perinotochordal tissue from both halves of a segment (Dalgleish, 1985; Bagnall et al., 1988). It is also known that the axon pathway within the sclerotome differs from the barrier regions in that it exhibits a lower rate of proliferation (Dalgeish, 1985) and a higher incidence of cell death (Tosney et al., 1988).

The molecular markers for barrier function that we have identified also appear to be early markers for prechondrogenic differentiation. Several lines of evidence suggest that PNA binding molecules are typical of prechondrogenic tissues. First, PNA binding sites have been localized to cartilage forming regions prior to the onset of overt chondrogenesis. As we have shown here, PNA binds the sclerotome, girdle, and limb core at very early stages of development, which is in agreement with previous studies that focused on the prechondrogenic core of the limb in chick (Aulthouse and Solursh, 1987; Hurle et al., 1988) and mouse (Zimmermann and Thies, 1984), as well as the prechondrogenic centers of the head mesenchyme in the chick (Liu and Layer, 1984). Second, PNA binding molecules are also expressed in prechondrogenic cellular aggregates in vitro prior to the expression of other chondrogenic markers such as intense alcian blue staining or type II collagen immunoreactivity (Aulthouse and Solursh, 1987). Finally, we have shown that the preferential expression of PNA binding molecules in the perinotochordal mesenchyme is abolished following notochord deletion (Tosney and Oakley, 1990). Since chondrogenic differentiation in the sclerotome has been shown to be dependent on the notochord (Kosher and Lash, 1975; Lash and Vasan, 1978; Cheney and Lash, 1981), our result suggests that PNA binding molecules are coordinately regulated with chondrogenic development. However, it is also noteworthy that neither PNA nor C-6-S is an exclusive marker for prechondrogenic development since both probes also label the axial dermis and spinal cord and since PNA labels nonchondrogenic regions of the limb bud including the ectoderm and apical ectodermal ridge.

Although the carbohydrate-specific probes used here are clearly recognizing some component of early prechondrogenic tissue, we do not know the precise identity of the molecules detected. However, several potential candidates among the various chondroitin sulfate proteoglycans (CSPGs) of cartilage can be considered based on a comparison of our results with previous findings. First, although CSPGs are major constituents of mature cartilage, it is unlikely that the C-6-S-specific antibody used here is binding exclusively to the large aggregating CSPG of mature cartilage, since this CSPG is not expressed in the core of the limb until stage 25 (Shinomura et al., 1984; Stirpe and Goetinck, 1989). Moreover, this CSPG has keratan sulfate side chains (see Ruoslahti, 1988) and we were unable to colocalize keratan sulfate immunoreactivity with that of C-6-S in the early limb bud. Second, the spatial and temporal expression patterns in the limb that we have described here are similar to those described by Kimata and colleagues for a large chondroitin sulfate proteoglycan, termed PG-M, which is rich in C-6-S moieties and devoid of keratan sulfate chains. The expression of PG-M precedes the mesenchymal condensation that leads to overt chondrogenic differentiation (Kimata et al., 1986; Shinomura et al., 1990). PG-M is also expressed by embryonic fibroblasts and may be the chick equivalent of a human fibroblast CSPG, termed versican, which has recently been cloned (Zimmerman and Ruoslahti, 1989). Third, it is also possible that the C-6-S-specific probe recognizes the cytotactin binding proteoglycan identified by Edelman and colleagues since this CSPG is also preferentially expressed in the posterior sclerotome during early motor outgrowth (Tan et al., 1987). This CSPG is expressed by mature chondrocytes (Hoffman et al., 1988) but it is presently unclear whether the cytotactin binding CSPG is identical with or related to PG-M or the large aggregating CSPG of mature cartilage.

It also seems unlikely that the two probes used in this study are recognizing different epitopes on the same molecule. One of the candidate molecules, the cytotactin binding CSPG, has been reported to have both CS side chains and PNA binding sites (Tan et al., 1987; Crossin et al., 1989). However, we found that although PNA binding sites and C-6-S immunoreactivity are largely codistributed, the patterns of expression are clearly not identical. In fact, PNA binding sites are generally more widely distributed than is C-6-S immunoreactivity. Similar differences have also been noted by Solursh, Ki- 
mata, and colleagues in comparing PNA binding patterns with the distribution of PG-M in early limb buds. These findings suggest that molecules other than CSPGs also bear the PNA binding epitope. The conclusion that the two barrier markers are recognizing more than one molecule is also supported by the fact that other PNA binding molecules smaller than either PG-M or the cytotactin binding CSPG have been identified in extracts of somitic (Davies et al., 1990) and limb bud mesenchyme (Shinomura et al., 1990).

Although it is unlikely that a single molecular entity is recognized by both probes, our results do suggest an interaction between PNA binding molecules and CSPGs. We found that PNA binding molecules are stabilized by CPC, which is known to precipitate glycosaminoglycans (Kvist and Finnegan, 1970; Young et al., 1989). This result suggests that CSPGs and PNA binding molecules are coprecipitated during fixation. Although the nature of such an interaction is unknown, PNA binding molecules could serve as ligands for CSPGs since the core proteins of both versican and the CSPG of mature cartilage contain lectin-like domains with binding affinities for extended galactose-bearing epitopes (Halberg et al., 1988; Zimmerman and Ruoslahti, 1989).

Regardless of the specific identities of the molecules detected with the probes used here, it is clear that barrier tissues all express epitopes associated with early prechondrogenic differentiation during the period when growth cones are avoiding these tissues. We suggest that growth cones may be capable of recognizing and avoiding prechondrogenic tissues. The fact that these tissue precursors can be distinguished within an otherwise homogeneous mesenchyme by the expression of specific markers suggests a possible molecular basis for this recognition.

\section{Expression of Barrier Markers in the CNS}

The barrier markers we have identified are not only expressed in axon barriers in the periphery, but they are also expressed in specific regions of the CNS. For example, we have shown here that both markers are expressed in the roof plate of the spinal cord, a putative barrier to commissural and DRG axons in the rat (Snow et al. 1990a). PNA binding sites have also been recently shown to define the borders between rhombomeres in the chick hindbrain (Layer and Alber, 1990), which have been suggested to restrict neuronal migration (Fraser et al., 1990; Lumsden, 1990). Similarly, both PNA binding sites (Cooper and Steindler, 1986; Steindler and Cooper, 1987) and the cytotactin binding CSPG (Crossin et al., 1989) are transiently expressed by the cells that form the walls between the functional units (barrels) of the somatosensory cortex that are associated with the vibrissae of the face in the rodent. This pattern of expres- sion has been detected during the ingrowth of thalamocortical axons to the barrel hollows and persists as cortical dendrites are elaborated within the barrel hollows. On the basis of these correlations, it has been suggested that the barrel walls maintain functional domains by inhibiting cell migration and the crossing of barrel walls by afferents and dendrites (Steindler et al., 1989; Crossin et al., 1989). These studies as well as others (Steindler and Cooper, 1987; Steindler et al., 1988) all suggest that the expression of specific carbohydrate epitopes is associated with the functional subdivision of the CNS. What is unclear from these studies, however, is whether the boundaries identified by these probes do, in fact, serve to constrain process outgrowth and cellular migration. In the case of the peripheral nervous system, we have provided strong experimental evidence that barrier tissues do constrain axon outgrowth. Similar experimental approaches will be necessary to determine if the same is true for the putative barriers of the CNS.

The barrier markers we have identified are also expressed at the lateral margins of the early spinal cord which serves as a pathway for commissural axons during this period of development (Holley and Silver, 1987; Yaginuma et al., 1991). Although the lateral marginal zone is clearly not a barrier to commissural outgrowth, it may be recognized as such by other early populations of spinal cord interneurons since they turn away from the lateral marginal zone after experimental rotation of the spinal cord (Yaginuma and Oppenheim, 1991). If the lateral marginal zone is indeed a barrier for some spinal interneurons, the population-specific behavior of commissural growth cones may be due to the chemotactic influence of the floor plate (Tessier-Levigne et al., 1988; Yaginuma and Oppenheim, 1991) or commissural growth cones may lack the capacity to recognize barrier tissues.

\section{Cellular and Molecular Mechanisms of Barrier Function}

The correlation between barrier function and specific carbohydrate expression, while intriguing, does not necessarily imply that these sugar moities, or even the proteins that bear them, are mediators of barrier function. However, several lines of evidence directly implicate PNA binding molecules as mediators of barrier function. First, barrier function and differential PNA binding are coordinately abolished in the perinotochordal mesenchyme following notochord deletion, which suggests that the expression of PNA binding or coregulated molecules is essential for barrier function (Tosney and Oakley, 1990). Second, glycoprotein fractions extracted from somites and isolated by PNA affinity chromatography completely inhibit sensory growth cone motility in vitro when presented in liposomes. The active components of these extracts are two glycoproteins (48 and 55 
$\mathrm{kDa}$ ) that are preferentially expressed in the posterior sclerotome (Davies et al., 1990). Third, a PNA binding glycoprotein $(33 \mathrm{kDa})$ has also been isolated from posterior tectal membranes. This glycoprotein causes the collapse of temporal retina growth cones when presented in liposomes (Stahl et al., 1990). While these studies implicate PNA binding glycoproteins in barrier function, the absence of PNA binding sites in the posterior sclerotome of the quail embryo (Asomato et al., 1990; and present results) suggests that the PNA binding disaccharide (Gal $\beta$ 1-3 GalNac) is not essential for barrier function. It is currently unknown if differentially glycosylated forms of the glycoproteins identified by Davies et al. (1990) are expressed in the quail posterior sclerotome.

Similarly, a number of studies suggest that C-6-Sbearing molecules are directly involved in the avoidance of barrier tissues by axons and neural crest cells. Tissue culture studies of neurite outgrowth have shown that chondroitin sulfate (CS) is a poor substrate for sensory outgrowth and that CS, C-6-S, and CSPGs can block the growth promoting effects of fibronectin, laminin, and collagen (Carbonetto et al., 1983; Verna et al., 1989; Snow et al., 1990b). Moreover, both sensory neurites (Verna et al., 1989; Snow et al., 1990b) and motor neurites (Oakley and Tosney, unpublished observations) that are growing on permissive substrates will turn to avoid substrates that contain CSPGs. Furthermore, neural crest cell migration is also inhibited by CSPGs in vitro (Newgreen et al., 1986; Tan et al., 1987; Perris and Johansson, 1987, 1990). These results all suggest that the expression of CSPGs in barrier tissues could directly contribute to the avoidance of these regions by axons and neural crest cells in vivo.

How might the expression of specific molecules be translated into avoidance behavior by axons and neural crest cells? Two different cellular mechanisms with very different implications for molecular function deserve consideration. First, as suggested by the work of Davies et al. (1990), growth cone collapse upon contact with barrier tissues could lead to avoidance behavior. Growth cone collapse is characterized by the complete inhibition of growth cone motility following contact with a specific cell type (Kapfhammer et al., 1986, Kapfhammer and Raper, 1987). The loss of motility is transient and thus strongly resembles the contact inhibition exhibited by a variety of cell types (see Trinkaus, 1984, 1985). This mechanism implies the existence of a specific receptor on all responding populations that interacts with a specific ligand expressed in barrier tissues. Two possible candidates for such ligands are PNA binding molecules and C-6-S-bearing molecules since these are expressed by all known barriers to axon advance. Alternatively, the avoidance of barrier tissues by growth cones and neural crest cells may be based on substratum preference. This mechanism entails the choice of one permissive substratum over another (Letourneau, 1975). A substratum preference mechanism implies that any or all molecules that contribute to the overall adhesivity or suitability of a substrate would be important (if not individually critical) factors in determining growth cone choice. Substratum preference may be particularly relevant to guidance by barrier function since there is growing evidence that CSPGs as well as other matrix components may restrict neurite outgrowth and cellular migration by blocking access to substrate adhesion molecules such as laminin and fibronectin by either masking the cellular binding sites on these substrate adhesion molecules (Laterra et al., 1980; Rich et al., 1981; Carbonetto et al., 1983; Yamagata et al., 1986; Lewandowska et al., 1987; Verna et al., 1989; Yamagata et al., 1989; see Ruoslahti, 1988 for review) or by interacting with cell surface components that in turn block the receptors for these substrate adhesion molecules (Perris and Johansson, 1987, 1990).

It should be possible to distinguish between and establish the relative importance of these alternative cellular mechanisms by directly observing interactions between growth cones and barrier tissues. Once the nature of the cellular mechanism is defined, the problem of identifying the molecules responsible for growth cone avoidance behavior will be simplified.

This work was supported by NIH Grants NS-21308 and NS-27634. Robert Oakley was partially supported by NIH Training Grant HD07274 and by a Regent's fellowship from the University of Michigan. We thank Gianni Piperno and Bruce Caterson for providing monoclonal antibodies to acetylated $\alpha$-tubulin and keratan sulfate, respectively. We thank Denise Dehnbostel for technical assistance, David Bay for photographic assistance, and Richard Hume for helpful comments on the manuscript.

\section{REFERENCES}

Asamoto, K., NoJyo, Y., and Aoyama, H. (1990). Do peanut agglutinin receptors on somites control the behavior of neural cells? Dev. Growth Differ. 32, 91-96.

Aulthouse, A. L., and Solursh, M. (1987). The detection of a precartilage, blastema-specific marker. Dev. Biol. 120, 377-384.

Bagnall, K. M., Higgins, S. J., and SANDERs, E. J. (1988). The contribution made by a single somite to the vertebral column: Experimental evidence in support of resegmentation using the quail-chick chimaera model. Development 103, 69-85.

BRONNER-FrASER, M. (1986). Analysis of the early stages of trunk neural crest migration in avian embryos using monoclonal antibody HNK-1. Dev. Biol. 115, 44-55.

CarbonetTo, S., Gruver, M. M., and TuRner, D. C. (1983). Nerve fiber growth in cultures on fibronectin, collagen and glycosaminoglycan substrates. J. Neurosci. 3, 2324-2335.

CATERson, B., Christner, J. E., and BAKER, J. R. (1983). Identification of a monoclonal antibody that specifically recognizes corneal and skeletal keratan sulfate. J. Biol. Chem. 258, 8848-8854.

Caterson, B., Christner, J. E., Baker, J. R., and Couchman, J. R. (1985). Production and characterization of monoclonal antibodies directed against connective tissue proteoglycans. Fed. Proc. 44, 386393. 
CheneY, C. M., and LASH, J. W. (1981). Diversification within embryonic chick somites: Differential response to notochord. Dev. Biol. 81, 288-298.

ChITNIS, A. B., and KUWADA, J. Y. (1990). Axonogenesis in the brain of zebrafish embryos. J. Neurosci. 10, 1892-1905.

CoOPER, N. G. F., and STEINDLER, D. A. (1986). Lectins demarcate the barrel subfield in the somatosensory cortex of the early postnatal mouse. J. Comp. Neurol. 249, 157-169.

Couchman, J. R., Caterson, B., Christner, J. E., and Baker, J. R. (1984). Mapping of monoclonal antibody detection of glycosaminoglycans in connective tissues. Nature 307, 650-652.

Crossin, K. L., Hoffman, S., TaN, S. S., and Edelman, G. M. (1989). Cytotactin and its proteoglycan ligand mark structural and functional boundaries in somatosensory cortex of the early postnatal mouse. Dev. Biol. 136, 381-392.

DALGLEISH, A. E. (1985). A study of the development of thoracic vertebrae in the mouse assisted by autoradiography. Acta Anat. 122, 9198.

Davies, J. A., Cook, G. M. W., Stern, C. D., and KeYnes, R. J. (1990). Isolation from chick somites of a glycoprotein fraction causes collapse of dorsal root ganglion growth cones. Neuron 2, 11-20.

DehNBOSTEL, D., and TosneY, K. W. (1990). Initial motor axon outgrowth. Soc. Neurosci. Abst. 16, 1006.

Fraser, S., KeYnes, R., and LumSDen, A. (1990). Segmentation in the chick hindbrain is defined by cell lineage restrictions. Nature $\mathbf{3 4 4}$, 431-434.

Halberg, D. F., Proulx, G., Doege, K., Yamada, Y., and Drickamer, K. (1988). A segment of the cartilage proteoglycan core protein has lectin-like activity. J. Biol. Chem. 263, 9486-9490.

HAMBURGER, V., and Hamilton, H. L. (1951). A series of normal stages in the development of the chick embryo. J. Morphol. 88, 49-92.

Hofrman, S., Crossin, K. L., and Edelman, G. M. (1988). Molecular forms, binding functions, and developmental expression patterns of cytotactin and cytotactin-binding proteoglycan, an interactive pair of extracellular matrix molecules. J. Cell Biol. 106, 519-532.

HoLLEY, J. A., and Silver, J. (1987). Growth of pioneering chick spinal cord axons. Dev. Biol. 123, 357-388.

HuRle, J. M., Ros, M. A., and HiNCHLIFFE, J. R. (1988). Spatial and temporal changes in the pattern of glycosylation of the developing chick limb tissue components as revealed by fluorescent conjugated lectin probes. Cell Differ. 24, 149-158.

Kapfhammer, J. P., Grunewald, B. E., and RaPer, J. A. (1986). The selective inhibition of growth cone extension by specific neurites in culture. J. Neurosci. 6, 2527-2534.

KAPFHAMmER, J. P., and RAPER, J. A. (1987). Collapse of growth cone structure on contact with specific neurites in culture. J. Neurosci. 7, 201-213.

KeYNES, R. J., and StERN, C. D. (1984). Segmentation in the vertebrate nervous system. Nature 310, 786-789.

Kimata, K., OtKe, Y., Tani, K., Shinomura, T., Yamagata, M., UriTANI, M., and SUZUKI, S. (1986). A large chondroitin sulfate proteoglycan (PG-M) synthesized before chondrogenesis in the limb bud of the chick embryo. J. Biol. Chem. 261, 13,517-13,525.

KOSHER, R. A., and LASH, J. W. (1975). Notochordal stimulation of in vitro somite chondrogenesis before and after enzymatic removal of perinotochordal materials. Dev. Biol. 42, 362-378.

KRYostoseK, A., and SeEDS, N. W. (1981). Plasminogen activator release at the neuronal growth cone. Science 213, 1532-1534.

Kvist, T. N., and FinNeGaN, C. V. (1970). The distribution of glycosaminoglycans in the axial region of the developing chick embryo. $J$. Exp. Zool. 175, 221-240.

LANCE-JONES, C. J., and LANDMESSER, L. T. (1981a). Pathway selection by chick lumbosacral motoneurons during normal development. Proc. R. Soc. London B 214, 1-18.

LANCE-JoNES, C. J., and LANDMESSER, L. T. (1981b). Pathway selection by embryonic chick motoneurons in an experimentally altered environment. Proc. $R$. Soc. London B 214, 19-52.

LANDMESSER, L. (1988). Peripheral guidance cues and the formation of specific motor projections in the chick. In "From Message to Mind" (S. S. Easter, K. F. Barald, and B. M. Carlson, Ed.), pp. 121-133. Sinauer, Sunderland, MA.

LASH, J. W., and VASAN, N. S. (1978). Somite chondrogenesis in vitro. Dev. Biol. 66, 151-171.

LASKy, C., OAKLey, R. A., Dehnbostle, D., and ToSNEY, K. W. (1991). Experimental evidence that an inhibitory boundary delays neural crest migration. Soc. Neurosci. Abstr. 17, in press.

Laterra, J., ANSBaCher, R., and CulP, L. A. (1980). Glycosaminoglycans that bind cold-insoluble globulin in cell-substratum adhesion sites of murine fibroblasts. Proc. Natl. Acad. Sci. USA 77, 6662-6666.

LAYER, P. G., and ALRER, R. (1990). Patterning of chick brain vesicles as revealed by peanut agglutinin and cholinesterases. Development 109, 613-624.

LAYer, P. G., Alber, R., and RATHJen, F. G. (1988). Sequential activation of butyrulcholinesterase in rostral half somites and acetylcholinesterase in motoneurones and myotomes preceding growth of motor axons. Development 102, 387-396.

Letourneau, P. C. (1975). Cell to substratum adhesion and the guidance of axonal elongation. Dev. Biol. 44, 92-101.

Lewandowska, K., ChoI, H. U., RosenberG, L. C., Zardi, L., and CuLP, L. A. (1987). Fibronectin mediated adhesion of fibroblasts: Inhibition by dermatan sulfate proteoglycan and evidence for a cryptic glycosaminoglycan-binding domain. J. Cell Biol. 105, 14431454.

Lim, S. S., SammaK, P. J., and Borisy, G. G. (1989). Progressive and spatially differentiated stability of microtubules in developing neuronal cells. J. Cell Biol. 109, 253-263.

LIU, L., and LAYER, P. G. (1984). Spatio-temporal patterns of differentiation of whole heads of the embryonic chick as revealed by binding of a FITC-coupled peanut agglutinin (FITC-PNA). Dev. Brain Res. $12,173-182$.

LORING, J. F., and ERICKson, C. A. (1987). Neural crest cell migratory pathways in the chick embryo. Dev. Biol. 121, 230-236.

Lotan, R., Skutelsky, E., DanoN, D., and Sharon, N. (1975). The purification, composition and specificity of the anti-T lectin from peanut (arachis hypogaea). J. Biol. Chem. 250, 8518-8523.

LUMSDEN, A. (1990). The cellular basis of segmentation in the developing hindbrain. Trends Neurosci. 13, 329-335.

Newgreen, D. F., Powell, M. E., and Moser, B. (1990). Spatiotemporal changes in HNK-1/L2 glycoconjugates on avian embryo somite and neural crest cells. Dev. Biol. 139, 100-120.

Newgreen, D. F., SCheEL, M., and KASTNER, V. (1986). Morphogenesis of sclerotome and neural crest in avian embryos. In vivo and in vitro studies on the role of notochordal extracellular material. Cell Tissue Res. 244, 299-313.

PerRIs, R., and Johansson, S. (1987). Amphibian neural crest migration on purified extracellular matrix components: A chondroitin sulfate proteoglycan inhibits locomotion on fibronectin substrates. J. Cell Biol. 105, 2511-2521.

PerRIS, R., and JoHANSSON, S. (1990). Inhibition of neural crest migration by aggregating chondroitin sulfate proteoglycans is mediated by their hyaluronan-binding region. Dev. Biol. 137, 1-12.

PerRis, R., Krotoski, D., LALlier, T., Domingo, C., SORRel, J. M., and BRONNER-Fraser, M. (1991). Spatial and temporal changes in the distribution of proteoglycans during avian neural crest development. Development 111, 583-599.

Piperno, G., LeDizet, M., and Chang, X. (1987). Microtubules containing acetylated $\alpha$-tubulin in mammalian cells in culture. J. Cell Biol. 104, 289-302.

PitTMan, R. N. (1985). Release of plasminogen activator and a cal- 
cium-dependent metalloprotease from cultured sympathetic and sensory neurons. Dev. Biol. 110, 91-101.

Rich, A. M., Pearlstein, E., Weissmann, G., and Hoffrstein, S. T. (1981). Cartilage proteoglycans inhibit fibronectin mediated adhesion. Nature 293, 224-226.

RICKMANN, M., FAUCET, J. W., and KEYNES, R. J. (1985). The migration of neural crest cells and the growth of motor axons through the rostral half of the chick somite. J. Embryol. Exp. Morphol. 90, 437455.

Rogers, S. L., Enson, K. J., Letourneau, P. C., and McLoon, S. C. (1986). Distribution of laminin in the developing peripheral nervous system of the chick. Dev. Biol. 113, 429-435.

Ruoslahti, E. (1988). Structure and biology of proteoglycans. Annu. Rev. Cell Biol. 4, 229-255.

Schroeter, S., LASKy, C. J., OAKLEY, R. A., Erickson, C. A., and TOSNEY, K. W. (1990). Evidence for the delineation of neural crest migration pathways by inhibitory boundaries. Soc. Neurosci. Abstr. $16,313$.

Shinomura, T., Jensen, K. L., Yamagata, M., Kimata, K., and SoLURSH, M. (1990). The distribution of mesenchyme proteoglycan (PG-M) during wing bud outgrowth. Anat. Embryol. 181, 227-233.

Shinomura, T., Kimata, K., OIKe, Y., Maeda, N., Yano, S., and SUZUKI, S. (1984). Appearance of distinct types of proteoglycan in a well defined temporal and spatial pattern during early cartilage formation in the chick limb. Dev. Biol. 103, 211-220.

Snow, D. M., Lemmon, V., Carrino, D. A., Caplan, A. I., and Silver, J. (1990b). Sulfated proteoglycans in astroglial barriers inhibit neurite outgrowth in vitro. Exp. Neurol. 109, 111-130.

SNow, D. M., Stenndler, D. A., and Silver, J. (1990a). Molecular and cellular characterization of the glial roof plate of the spinal cord and optic tectum: A possible role for a proteoglycan in the development of an axon barrier. Dev. Biol. 138, 359-376.

STAHL, B., Muller, B., von BoXberg, Y., CoX, E. C., and BONHOFfer, F. (1990). Biochemical characterization of a putative axonal guidance molecule of the chick visual system. Neuron 5, 735-743.

Steindler, D. A., and Cooper, N. G. F. (1987). Glial and glycoconjugate boundaries during postnatal development of the central nervous system. Dev. Brain Res. 36, 27-38.

Steindler, D. A., CoOper, N. G. F., Faissner, A., and Schachner, M. (1989). Boundaries defined by adhesion molecules during development of the cerebral cortex: The J1/tenascin glycoprotein in the mouse somatosensory cortical barrel field. Dev. Biol. 131, 243-260.

Steindler, D. A., OBrien, T. F., and Cooper, N. G. F. (1988). Glycoconjugate boundaries during early postnatal development of the neostriatal mosaic. J. Comp. Neurol. 267, 357-369.

STERN, C. D., and KEYNES, R. J. (1987). Interactions between somite cells: The formation and maintenance of segment boundaries in the chick embryo. Development 99, 261-272.

STERN, C. D., SisodiYA, S. M., and KeYNEs, R. J. (1986). Interactions between neurites and somite cells: Inhibition and stimulation of nerve growth in the chick embryo. J. Embryol. Exp. Morphol. 91, 209-226.

Stirpe, N. S., and GoetinCK, P. F. (1989). Gene regulation during cartilage differentiation: Temporal and spatial expression of link protein and cartilage matrix protein in the developing limb. Development 107, 23-33.

Swanson, G. J., and LEwIS, J. (1982). The timetable of innervation and its control in chick wing bud. J. Embryol. Exp. Morphol. 71, 121-137.

TAN, S. S., Crossin, K. L., HoffmaN, S., and Edelman, G. M. (1987). Asymmetric expression in somites of cytotactin and its proteoglycan ligand is correlated with neural crest distribution. Proc. Natl. Acad. Sci. USA 84, 7977-7981.

TANaKa, H., Agata, A., and OBata, K. (1989). A new membrane antigen revealed by monoclonal antibodies is associated with motoneuron axonal pathways. Dev. Biol. 132, 419-435.
Teillet, M-A., KALCheim, C., and Le Douarin, N. (1987). Formation of the dorsal root ganglia in the avian embryo: Segmental origin and migratory behavior of neural crest progenitor cells. Dev. Biol. 120, 329-347.

Tessier-Lavigne, M., Placzek, M., Lumsden, A. G. S., Dodd, J., and Jessell, T. M. (1988). Chemotropic guidance of developing axons in the mammalian central nervous system. Nature 336, 775-778.

Tosney, K. W. (1987). Proximal tissues and patterned neurite outgrowth at the lumbosacral level of the chick embryo: Deletion of the dermamyotome. Dev. Biol. 122, 540-588.

TosNEy, K. W. (1988a). Proximal tissues and patterned neurite outgrowth at the lumbosacral level of the chick embryo: Partial and complete deletion of the somite. Dev. Biol. 127, 266-286.

TosNEY, K. W. (1988b). Somites and axon guidance. Scan. Microsc. 2 (88), 427-442.

Tosney, K. W. (1991). Cells and cell interactions that guide motor axons in the developing chick embryo. Bioessays 13, 1-7.

TOSNEY, K. W., and LANDMESSER, L. T. (1984). Pattern and specificity of axonal outgrowth following varying degrees of chick limb bud ablation. J. Neurosci. 4, 2158-2527.

TOSNEY, K. W., and LANDmesser, L. T. (1985). Development of the major pathways for neurite outgrowth in the chick hindlimb. Dev. Biol. 109, 193-214.

TOSNEY, K. W., and OAKLEY, R. A. (1990). The perinotochordal mesenchyme acts as a barrier to axon advance in the chick embryo: Implications for a general mechanism of axon guidance. Exp. Neurol. 109, $75-89$.

Tosney, K. W., Schroeter, S., and Pokrzywinski, J. A. (1988). Cell death delineates axon pathways in the hindlimb and does so independently of neurite outgrowth. Dev. Biol. 130, 558-572.

Tosney, K. W., Watanabe, M., Landmesser, L., and Rutishauser, U. (1986). The distribution of NCAM in the chick hind limb during axon outgrowth and synaptogenesis. Dev. Biol. 114, 437-452.

TRINKaus, J. P. (1984). “Cells into Organs," second ed., pp. 246-253. Prentice-Hall, Englewood Cliffs, NJ.

TrINKaUS, J. P. (1985). Further thoughts on directional cell movement during morphogenesis. J. Neurosci. Res. 13, 1-19.

VERNA, J. M., FiChaRD, A., and SAXOD, R. (1989). Influence of glycosaminoglycans on neurite morphology and outgrowth patterns in vitro. Int. J. Dev. Neurosci. 7, 389-399.

Yaginuma, H., Homma, S., KunZI, R., and OPPENHeIm, R. W. (1991). Pathfinding of commissural interneurons in the chick embryo: A light and electron microscopic study. J. Comp. Neurol. 304, 78-102.

YAGINUMA, H., and OPPENHEIM, R. W. (1991). An experimental analysis of in vivo guidance cues used by axons of spinal interneurons in the chick embryo: Evidence for chemotropism and related guidance mechanisms. J. Neurosci, in press.

Yamagata, M., Suzuki, S., AkIYama, S. K., Yamada, K. M., and KIMATA, K. (1989). Regulation of cell substrate adhesion by proteoglycans immobilized on extracellular substrates. J. Biol. Chem. 264, 8012-8018.

Yamagata, M., Yamada, K. M., Yoneda, M., Suzukı, S., and Kimata, K. (1986). Chondroitin sulfate proteoglycan (PG-M like proteoglycan) is involved in the binding of hylauronic acid to cellular fibronectin. J. Biol. Chem. 261, 13,526-13,535.

Young, H. E., Young, V. E., and Caplan, A. I. (1989). Comparison of fixatives for maximal retention of radiolabeled glycoconjugates for autoradiography, including use of sodium sulfate to release unincorporated ${ }^{35}$ S] sulfate. $J$. Histochem. Cytochem. 37, 223-228.

ZIMMERMANN, B., and THIES, M. (1984). Alterations of lectin binding during chondrogenesis of mouse limb buds. Histochemistry 81, 353361.

Zimmerman, D., and RouslathI, E. (1989). Multiple domains of the large fibroblast proteoglycan, versican. EMBO J. 8, 2975-2981. 